The University of Maine

DigitalCommons@UMaine

Publications

Senator George J. Mitchell Center for Sustainability

Solutions

$11-2014$

\title{
Development of a Stakeholder-driven Spatial Modeling Framework for Strategic Landscape Planning using Bayesian Networks across two Urban-Rural Gradients in Maine, USA
}

Spencer Meyer

University of Maine

Michelle Johnson

Robert Lilieholm

Christopher Cronan

Follow this and additional works at: https://digitalcommons.library.umaine.edu/ mitchellcenter_pubs

Part of the Natural Resources Management and Policy Commons, and the Sustainability Commons

\section{Repository Citation}

Meyer, Spencer; Johnson, Michelle; Lilieholm, Robert; and Cronan, Christopher, "Development of a Stakeholder-driven Spatial Modeling Framework for Strategic Landscape Planning using Bayesian Networks across two Urban-Rural Gradients in Maine, USA" (2014). Publications. 86.

https://digitalcommons.library.umaine.edu/mitchellcenter_pubs/86

This Article is brought to you for free and open access by DigitalCommons@UMaine. It has been accepted for inclusion in Publications by an authorized administrator of DigitalCommons@UMaine. For more information, please contact um.library.technical.services@maine.edu. 
Development of a Stakeholder-driven Spatial Modeling Framework for Strategic Landscape Planning using Bayesian Networks across two Urban-Rural Gradients in Maine, USA

Spencer R. Meyer ${ }^{\mathrm{a} *}$, Michelle L. Johnson ${ }^{\mathrm{b}}$, Robert J. Lilieholm ${ }^{\mathrm{c}}$, and Christopher S. Cronan ${ }^{\mathrm{d}}$

${ }^{a}$ Center for Research on Sustainable Forests, University of Maine,

Orono, ME 04469-5755, U.S.A.; +1 207.852.3171; spencer.meyer@gmail.com

${ }^{\mathrm{b}}$ Ecology and Environmental Science Program, University of Maine,

Orono, ME 04469-5755, U.S.A.; +1 207.852.1181; michelle.I.johnson@maine.edu

${ }^{c}$ School of Forest Resources, University of Maine,

Orono, ME 04469-5755, U.S.A.; +1 207.581.2896; robert.lilieholm@maine.edu

d School of Biology and Ecology, University of Maine,

Orono, ME 04469-5722, U.S.A.; +1 207.581.2618; chris.cronan@umit.maine.edu

* Corresponding author 
ABSTRACT

Land use change results from frequent, independent actions by decision-makers working in isolation, often with a focus on a single land use. In order to develop integrated land use policies that encourage sustainable outcomes, scientists and practitioners must understand the specific drivers of land use change across mixed land use types and ownerships, and must consider the combined influences of biophysical, economic, and social factors that affect land use decisions. In this analysis of two large watersheds covering a total of 1.9 million hectares in Maine, U.S.A., we co-developed with groups of stakeholders land use suitability models that integrated four land uses: economic development, ecosystem protection, forestry, and agriculture. We elicited stakeholder knowledge to: (1) identify generalized drivers of land use change; (2) construct Bayesian network models of suitability for each of the four land uses based on site-level factors that affect land use decisions; and (3) identify thresholds of suitability for each factor and give relative weights to each factor. We then applied 12 distinct Bayesian models using 99 spatially explicit, empirical socio-economic and biophysical datasets to predict spatially the suitability for each of our four land uses on a $30 \mathrm{x}$ $30 \mathrm{~m}$ pixel basis across 1.9 million hectares. We evaluated both the stakeholder engagement process and the land use suitability maps. Results demonstrated the potential efficacy of these models for strategic land use planning, but also revealed that trade-offs occur when stakeholder knowledge is used to augment limited empirical data. First, stakeholder-derived Bayesian land use models can provide decision-makers with relevant insights about the factors affecting land use change. Unfortunately, these models are not 
easily validated for predictive purposes. Second, integrating stakeholders throughout different phases of the modeling process provides a flexible framework for developing localized or generalizable land use models depending on the scope of stakeholder knowledge and available empirical data. The potential downside is that this can lead to more complex models than anticipated. The trade-offs between model rigor and relevance suggest an adaptive management approach to modeling is needed to improve the integration of stakeholder knowledge into robust land use models.

\section{KEYWORDS}

Bayesian networks; conservation; land use planning; stakeholder engagement; natural resource management; land use suitability 


\section{INTRODUCTION}

A major goal of land use change research is to develop models for improving the ability to predict and to interpret the patterns and impacts of human development on natural landscapes across multiple ownership types and spatial scales. This information can help inform and guide land use planning and policy development to support desired outcomes in a region. In order to be most effective, land use change models should: (1) identify the specific drivers of land use change across mixed landscapes; (2) consider the combined influences of biophysical suitability, economic viability, and socio-political feasibility on future land use patterns; and (3) represent small-scale behaviors that underlie larger-scale patterns (Kok and Veldkamp, 2001; Verburg et al., 2002). This paper presents a stakeholder-driven modeling framework for identifying these specific drivers of local behaviors and evaluating the aggregated patterns across two large watersheds in Maine.

Worldwide, development pressures have spurred numerous land use studies to assess the vulnerability and susceptibility of different regions to various development pressures (Baker et al., 2004; Stein et al., 2005, 2009; Turner et al., 2007; Verburg et al., 2002). In particular, the U.S. Forest Service's Forests on the Edge studies (Stein et al., 2005, 2009; White et al., 2009) have sought to identify regions in the U.S. where urbanization is threatening forest cover and associated ecosystem services. Conservation planning has well-defined principles for protecting land from anthropogenic disturbances and other land use changes (Margules and Pressey, 
2000; McDonald, 2009; Miller et al., 2009). However, those principles typically focus on designing systems that prevent development in order to protect biological integrity and ecosystem services (Newburn et al., 2005), thereby pitting development against ecosystem protection and/or natural resource management. As a result, such studies may provide little guidance for decisionmakers seeking to balance conservation with socio-political and economic objectives. A major challenge is to evaluate simultaneously the suitability of a heterogeneous landscape for development, ecosystem protection, and natural resource management in order to identify combinations that meet demands for alternative land uses. Attaining such a holistic approach is difficult given the diversity of stakeholders and the wide range of behaviors governing the interactions of social, economic, and ecological drivers of different land uses.

\subsection{Stakeholder Involvement in Decision Support for Land Use Planning}

Despite the growing inclusion of stakeholders in land use planning efforts (Steiner, 1990), a disconnect remains between the ability of planners to develop well-designed land use plans and the ability of policy-makers, regulators, and citizens to implement such plans (Knight et al., 2008; te Brömmelstroet, 2009). To bridge this gap, scientists and practitioners must derive planning tools that are credible, salient, and legitimate in the eyes of decision-makers (Cash et al., 2003) and useful to practitioners (te Brömmelstroet, 2009). Incorporating stakeholder knowledge into land use analyses lends credibility and relevance, and may create 
critical buy-in which can help mitigate distrust and resistance during plan implementation (Gray et al., 2012; Krueger et al., 2012;

Voinov and Bousquet, 2010;). Often what is ideal from a planning perspective does not meet the needs of individual decision makers (e.g., landowners). For instance, Downs (2005) showed that even though Smart Growth principles have strong appeal in theory, they often fail to be implemented because of a disconnect between what is desirable at a large scale, and the willingness of individuals to make small-scale decisions to achieve those outcomes.

Martin et al. (2012) reviewed the status of efforts to integrate expert knowledge with conservation science, and cited problems of complexity, limited data, and the time-sensitive nature of decision-making as key reasons to include experts. These reasons are also relevant to land use planning, which often suffers from similar challenges. Land use planning relies heavily on complex interactions among actors, economic incentives, regulations, and biophysical characteristics of the landscape. Martin et al. (2012) argued for rigorous, scientific methods of eliciting expert knowledge, and provided a set of best practices, including gathering both uncertainty and best estimates together, identifying a method of weighting and combining judgments, and providing feedback to experts throughout the process.

Others have addressed the difficulties of integrating expert knowledge in modeling processes (Krueger et al., 2012; Martin et al., 2012; O’Hagan, 2012; Price et al., 2012; Voinov and Bousquet, 2010;). For example, Krueger et al. (2012) provided a typology of 
expert-based models used in environmental modeling, and suggested objective ways to integrate expert opinion throughout multiple phases of modeling. Voinov and Bousquet (2010) argued that despite the challenges and uncertainty associated with using stakeholders in model development, including them is important for developing models that can inform and influence land use decisions.

In this study, we distinguish between experts and stakeholders, where the former provide either substantive, normative, or adaptive knowledge (Martin et al., 2012), and the latter offer not one of those, but also have influence either directly or indirectly over a particular process (e.g., practitioners such as real estate developers, city planners or forest managers). The literature is replete with studies that use experts (e.g., Verburg et al., 2002), but relatively few that engage stakeholders in model development (Hulse et al. 2004; Krueger et al., 2012; Price et al. 2012), where the difference is that experts are typically scientific thought leaders removed from decision-making while stakeholders may not hold the same theoretical knowledge as experts but are actively engaged in land use decisions. Hulse et al. (2004) found that outputs derived from scenarios based exclusively on expert opinion often lack political plausibility, while those developed only with stakeholders are difficult to quantify statistically. Scott (2011) cautioned against relying on stakeholders who have only weak connections to policy development because they may reduce the relevance otherwise gained by including stakeholders. In this study, we relied on both scientific experts and stakeholders engaged in decisionmaking. 
We also distinguish between models that incorporate expert and/or stakeholder knowledge at one point in the modeling process, versus those that use it in multiple stages of the model development process. For instance, some investigators have used expert (or stakeholder) knowledge to evaluate models structured and/or parameterized a priori by the research team (Beier et al., 2011; McCloskey et al., 2011). In contrast, other models have been co-developed by experts (or stakeholders) during multiple (e.g.,Swetnam et al., 2011), or even all phases of the modeling process (e.g., Price et al., 2012), including model specification, parameterization, and evaluation. These research partners also have a potential role in evaluating model validity, particularly for studies that project land change into the future where empirical data are often limited (Celio et al., 2012; Marcot, 2012; Parker et al., 2003).

1.2 Bayesian Networks and Land Use Suitability

Bayesian networks (BNs) are decision support tools that use Bayes' probability theory to describe decision processes by estimating the joint probability of an outcome based on prior information about input factors (Marcot et al., 2006). The flexibility of BNs allow researchers to supplement limited empirical data with expert knowledge, or in some cases where no empirical are available, the expert opinion supplants empirical data. BNs have roots in the fields of artificial intelligence (Charniak, 1991) and 
medical research (Spiegelhalter et al., 2013), but are now commonly used in environmental sciences (Marcot, 2012). For instance, BNs have been used to estimate habitat suitability (e.g., Smith et al., 2007), and have recently been employed in land use planning (e.g., Kocabas and Dragicevic, 2007).

A BN consists of an influence diagram that describes underlying behaviors in a process, and estimates the probability of an outcome as expressed by a posterior probability distribution (PPD). The influence diagram is comprised of nodes that represent factors of the process, connected by links that represent the influence each factor has on other factors, culminating in an output node which estimates the PPD. Marcot et al. (2006) used BNs to estimate the probability of capturing a species of squirrel (i.e., the outcome) based on habitat suitability and other factors (i.e., the nodes). Input "parent" nodes represent available empirical data, such as spatial data (e.g., GIS) or field measurements. Intermediate "child" nodes serve to group related input nodes, or factors.

The joint probabilities at the intermediate nodes are estimated through conditional probability tables (CPT), which define the causal relationship between each combination of multiple possible states of the parent nodes. Finally, outcome nodes estimate the overall probability of occurrence of a state. Each node is typically segmented into discrete states delineated either by distributions of underlying empirical data (as in the case of input nodes), or by the CPTs, in the case of intermediate nodes. The CPTs provide the 
expert- or stakeholder-derived probability that each combination of parent node states will occur, given a specified set of prior conditions.

BNs are particularly well suited to modeling situations where empirical data are limited and expert knowledge that approximates, or informs, the missing data can be elicited to augment the model (Marcot et al., 2006). There are multiple methods for integrating expert knowledge in BNs, depending on the type of missing information and the type of expert knowledge available. BNs are flexible and allow easy integration of new information as it becomes available, either through gathering of additional expert knowledge (e.g., larger sample of experts), or through additional empirical data. This aspect of BNs make them well-suited to adaptive management situations where new information is frequently sought to improve the performance and applicability of a model (Howes et al., 2010). Another important feature of BNs is the ability to evaluate the uncertainty of an outcome (i.e., through the probability estimate itself) and the sensitivity of the model to specific nodes.

Land use suitability analyses are used to identify areas of ideal conditions for future land uses given specific spatial and aspatial criteria. Malczewski (2004) provided a review of GIS-based suitability analyses, which have typically relied on rule-based models applied to stacked spatial input data. Due to their flexibility for modeling both simple and complex processes (Haines-Young, 2011), BNs are well-suited to suitability analyses when the goals are to: (1) identify the factors of land use suitability; and (2) use the 
relationships among factors to spatially predict suitability for a specific land use. Varkey et al. (2013) used BNs in a marine conservation planning study to balance input from stakeholders focused on development with those focused on ecosystem protection. McCloskey et al. (2011) developed a BN process for modeling suitability of development and ecosystem protection in a rural landscape. That study proposed a process for integrating stakeholder input, yet reported model results based solely on expert knowledge elicited from research team members.

\subsection{Study Objectives}

The work presented here builds and expands on the conceptual process presented by McCloskey et al. (2011) , which provided a framework for co-development of BNs that use stakeholder inputs to parameterize suitability models for four land uses: economic development, ecosystem protection, forestry, and agriculture (hereafter referred to as development, conservation, forestry, and agriculture, respectively). Our objectives were to: (1) identify the key social, economic, and biophysical factors that drive changes and determine spatial distributions in these four land uses in the Lower Penobscot River Watershed (LPRW) and the Casco Bay and Lower Androscoggin Watershed (CBLA) in central and southern Maine, U.S.A; (2) quantify and map land use suitabilities at a 30 x 30 m resolution across these two watersheds; and (3) build a replicable framework and method for large-scale, stakeholder- and datadriven modeling and analysis of land use suitability. 


\section{METHODS}

\subsection{Study Areas}

In order to compare both model structure and performance, we replicated our BN modeling across two similar large watersheds, each of which is characterized by an urban-rural gradient from the southern and downstream population centers to the northern and upstream forest-dominated, natural-resource driven landscape. These two watersheds were identified by Forests on the Edge as being among the top 15 watersheds in the U.S. expected to have the highest future impact of housing on forest cover (Stein et al. 2005). Later refinements to that study (Stein et al., 2009; White et al., 2009) reduced their U.S. ranking; however, reductions in forest cover of between $5 \%$ and $20 \%$ are still projected for these two watersheds.

\subsubsection{Lower Penobscot River Watershed (LPRW)}

The 1-million-hectare Lower Penobscot River Watershed (LPRW; Error! Reference source not found.) is a predominantly forested area wholly contained in the Northern Appalachian-Acadian ecoregion (Anderson et al., 2012), which is characterized by a 
transition forest of northern hardwoods and boreal tree species on lowland and mountainous topography. Based on the National Land Cover Dataset (NLCD; Fry et al., 2011), the watershed is $80 \%$ forested, $3.8 \%$ developed, and has $4.8 \%$ surface water, with the balance represented by a mix of wetlands, shrubland, and agricultural land.

LPRW is largely rural and is home to 164,000 people (12\% of state population) with an average density of 165 people/km², mostly concentrated in the Bangor, Brewer, Dover-Foxcroft, Lincoln, and Orono regional service centers (U.S. Census Bureau, 2010). Land use change in the region has been driven historically through forest management (Lilieholm et al., 2010) and localized urbanization around regional service centers (Brookings Institution, 2006; Stein et al., 2005; White et al., 2009). Nearly 10\% (98,075 ha) of the study area is permanently protected from development by a combination of public ownerships and conservation easements which provide legal restrictions on development.

\subsubsection{Casco Bay and Lower Androscoggin Watershed (CBLA)}

The 0.8-million-hectare Casco Bay and Lower Androscoggin Watershed (CBLA; Error! Reference source not found.) in southern Maine covers parts of the Northern Appalachian-Acadian, Lower New England-Northern Piedmont, and North Atlantic Coast Ecoregions (Anderson et al., 2012). This watershed is $74.7 \%$ forested, $8.9 \%$ developed, and has $5.3 \%$ surface water, with the balance 
in a mix of wetlands, shrubland, and agricultural land. This urban and rural watershed is home to 473,000 people ( $36 \%$ of state population) with an average density of 611 people $/ \mathrm{km}^{2}$, or 3.7 times denser than LPRW. The population is mostly concentrated in the Portland, Brunswick, Lewiston, and Auburn regional service centers (U.S. Census Bureau, 2010). Land use change in the watershed is driven by urbanization in the south and forestry and amenity development in the north. As with LPRW, nearly $10 \%$ $(76,518 \mathrm{ha})$ of the study area is permanently protected from development.

\subsection{Identifying Land Use Drivers through Stakeholder Engagement}

Through a series of focus groups, we elicited input about the drivers of land use change in each watershed from stakeholders representing the development, conservation, forestry, and agriculture sectors. Stakeholders for each land use were identified by their regional or statewide leadership in one or more land use categories. Focus group members included business leaders, NGO scientists and managers, educators, scientists, policy-makers, government officials, and members of the public. Each possessed varying degrees of indirect and direct influence on actual land use behaviors.

The four LPRW focus groups were held between June 2010 and March 2011, and the four CBLA focus groups were held in March and April 2012. Each focus group had between five and 10 participants (Table 1). At each focus group meeting, we used a 
combination of individual and group opinion elicitation techniques (see below) to gather information about the drivers of land use change in each region, and the specific factors that indicate suitability for a specific land use. In our earliest focus groups, a professional facilitator moderated the meetings - a role assumed by research team members in later focus groups.

Participants were first introduced to the concept of alternative futures modeling and were then exposed to the Willamette River Basin case study in Oregon (Baker et al., 2004) as an example. Participants were asked individually to identify specific spatially explicit factors that make land more or less suitable for their respective land uses. After collecting their individual responses, we moderated a group discussion to refine the list of drivers. Participants were encouraged to seek consensus, but when consensus could not be reached the facilitators called for a majority vote. Once key factors had been identified and accepted by the group, participants were asked to organize the factors into their relative functions and influences on each other. On rare instances when the process stalled, the group was prompted with examples that had been developed previously by the research team (McCloskey et al., 2011).

Netica $^{\circledR}$, a software package for constructing and modeling BNs, was used to construct the influence diagrams as described by Marcot et al. (2006) and McCloskey et al. (2011). Due to time constraints, the forestry and conservation focus groups for LPRW ended before model development was completed. In these cases, the meetings concluded having had the primary factors of 
suitability loosely organized into groups according to stakeholder input. Proficiency of the process grew over the course of the focus groups, and the final two groups in LPRW-agriculture and development and all of the CBLA focus groups-followed a slightly different process. In these cases, the research team led the stakeholders in real-time computer-based model specification by taking the factors identified earlier in the focus group and creating BN influence diagrams directly in Netica ${ }^{\circledR}$. As a result, complete but untested models were constructed before participants left the focus group. For forestry and conservation in LPRW, the Netica ${ }^{\circledR}$ diagrams were drafted by the research team following the focus group meeting based on the conceptual diagrams created during by the meeting. These diagrams were subsequently amended and approved by focus group participants.

Overall, we viewed our stakeholders as modelers themselves, rather than solely as providers of data or sources of feedback on our models. For example, the LPRW development group chose to construct three separate models of sub-categories of development-residential, amenity-based, and commercial (referred to collectively as development) - to better reflect the variation in factors of suitability for these specific types of development (e.g., amenity-based development, such as vacation homes, tends to be located farther from urban centers than residential development). The CBLA group similarly subdivided the development model, but did not choose to include an amenity development model. The stakeholder decision to split these models is justified by Marcot et al. (2006), who recommended splitting BNs when their structure is so complex that the final node is heavily influenced by error propagated through multiple intermediate levels of nodes. 


\subsection{Parameterizing the Models}

We used stakeholder information to specify and parameterize complete BNs that estimate the probability of suitability, on a $30 \mathrm{x}$ $30 \mathrm{~m}$ pixel basis (to correspond to the $30 \times 30 \mathrm{~m} \mathrm{NLCD}$, which we used as the input for several nodes), for each of our four land uses. The parent nodes represent the specific factors of suitability that were identified by the group, and are populated with derivatives of empirical spatial data (e.g., distance to roads, soil productivity, availability of water for irrigation). See the Appendix for a complete list of factors for all land use models and the specific definitions for the states of each factor. The child nodes represent the groupings of factors that the stakeholders collectively identified, and are based on CPTs developed from stakeholder surveys (see below). Finally, the suitability node (i.e., the bottom node at the culmination of each network) is estimated by processing the BN cases and CPTs. During the focus groups, stakeholders were encouraged to minimize the number of parent-child generations of factors in each BN, and also to keep the number of possible states for each node to no more than three. These limits were suggested to maintain parsimonious BNs, as recommended by Marcot et al. (2006).

Following each focus group, we acquired prior spatial data to populate the parent nodes representing each of the factors identified by stakeholders. In cases where we were unable to obtain spatial data for certain factors, we consulted the stakeholders 
and either discarded the factor entirely or replaced it with an agreed-upon surrogate. Further review was then sought from the stakeholders and additional refinements were made. At this time, stakeholders were also asked to identify the thresholds for converting the continuous prior values into discrete states (see Appendix). All input and intermediate nodes were classified into either two or three states. Three-state nodes typically followed a "high-medium-low" or "near-moderate-far" structure. Two-state nodes were more varied and included both "presence-absence" and "small-large" structures. Intermediate nodes all had three states, such that the parent nodes combined to produce high, medium, or low suitability scores for that intermediate node group. Final outcome nodes (e.g., suitability for forestry) used two-state binary structures where the probability of a "yes" score was considered the probability of suitability for each land use. Suitability input factors are shown in Figures 2 through 5 as parentless nodes (i.e., the highest order nodes) in the BN for each land use. The process of discretizing the factors into these states was guided by the research team with feedback and verification by stakeholders.

Next we used a survey, delivered both electronically and via mail, in which stakeholders and research team members were asked to rate the relative suitability of each discrete state of each parent node using a five-point interval scale, with one being "highly suitable" and five being "not suitable" for the given land use. In order to evaluate the relative suitability of every combination of states, we transformed the mean interval scores for each state combination into a distribution of percent probabilities according to the rubric in 
Figure 2 Bayesian network influence diagrams for development land used in the lower Penobscot River Watershed (LPRW). Input nodes (yellow rounded boxes), intermediate nodes (blue rectangle boxes), and the final outcome node (white rounded boxes), are shown for each of the $(A)$ residential, $(B)$ commercial development, and $(C)$ amenity development suitability models.

\section{A. Residential Development LPRW}

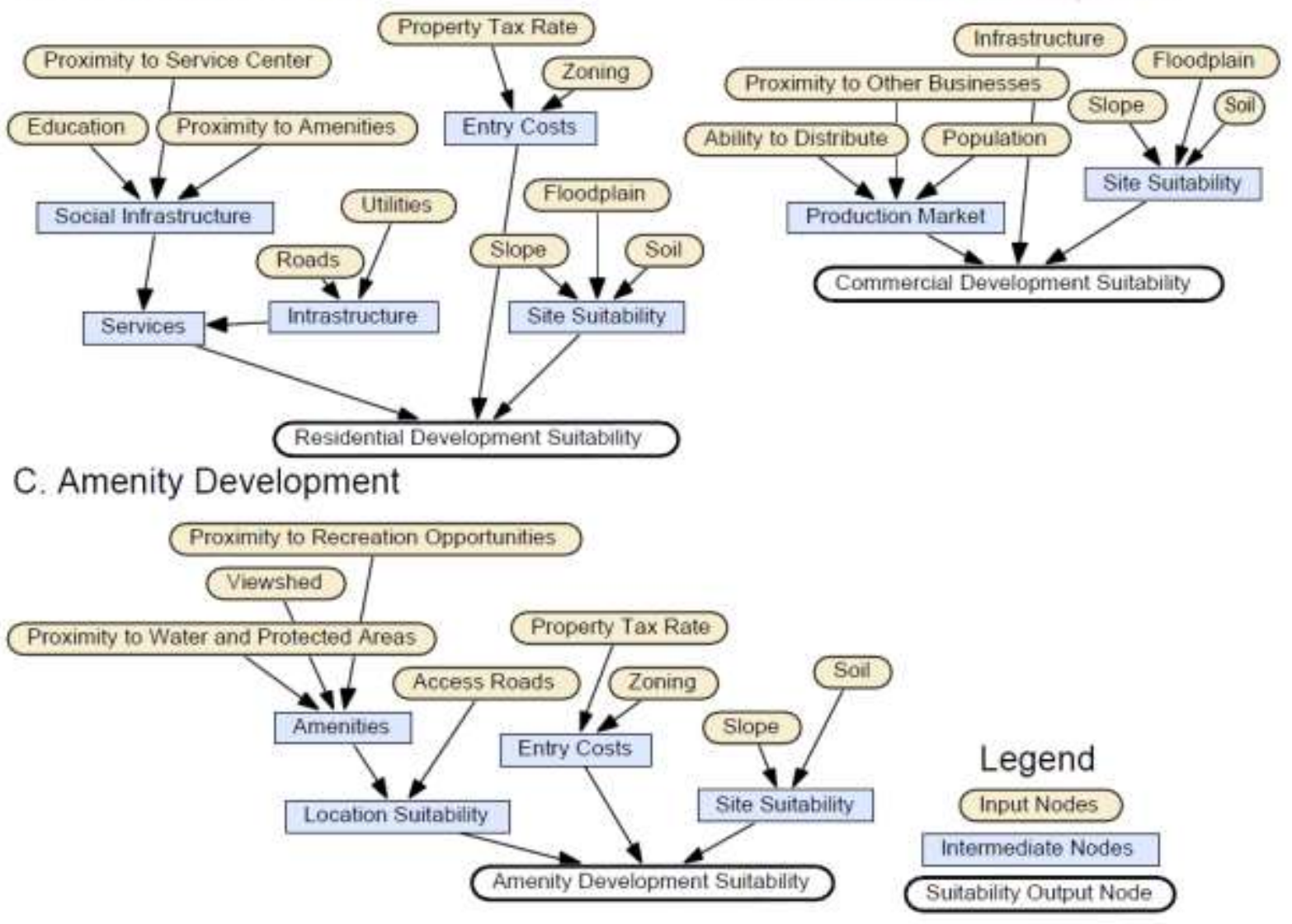


Figure 3 Bayesian network influence diagrams for development land uses in the Casco Bay and Lower Androscoggin Watershed (CBLA). Input nodes (yellow), intermediate nodes (blue) and the final outcome node (white) are shown for each of the $(A)$ residential development and (B) commercial development. (For interpretation of the referenced to color in this figure legend, the reader is referred to the final published version of this article.)

\section{CBLA}

\section{A. Residential Development}

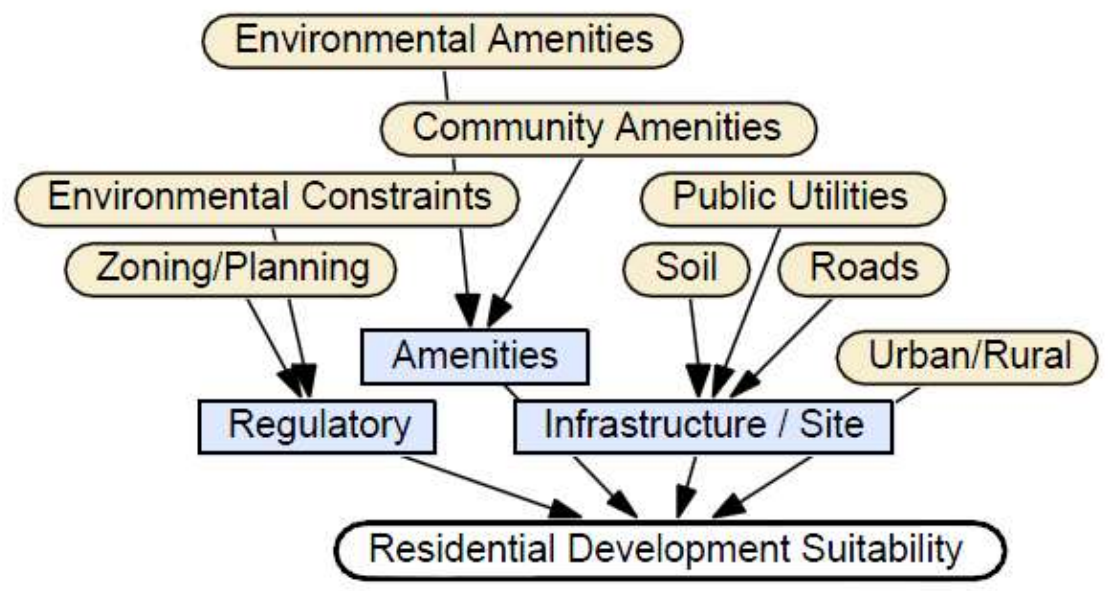

B. Commercial Development

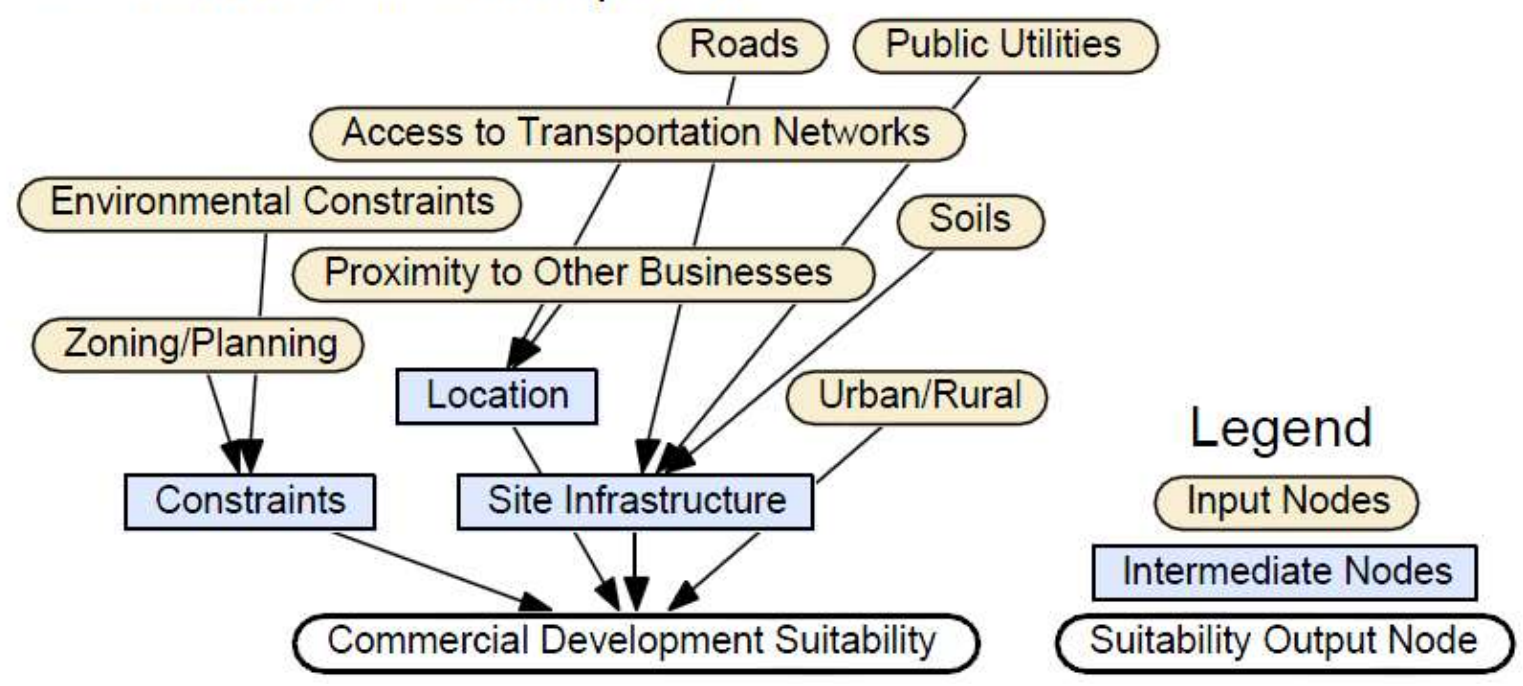


Figure 4 Bayesian network influence diagrams for forestry, agriculture and conservation land uses in the Lower Penobscot River Watershed (LPRW). Input nodes (yellow), intermediate nodes (blue), and the final outcome node (white) are shown for each of the (A) forestry, (B) agriculture, (C) conservation-local, and (D) conservation-landscape. (For interpretation of the references to color in this figure legend, the reader is referred to the final published version of this article.)

\section{A. Forest Management}

\section{LPRW}
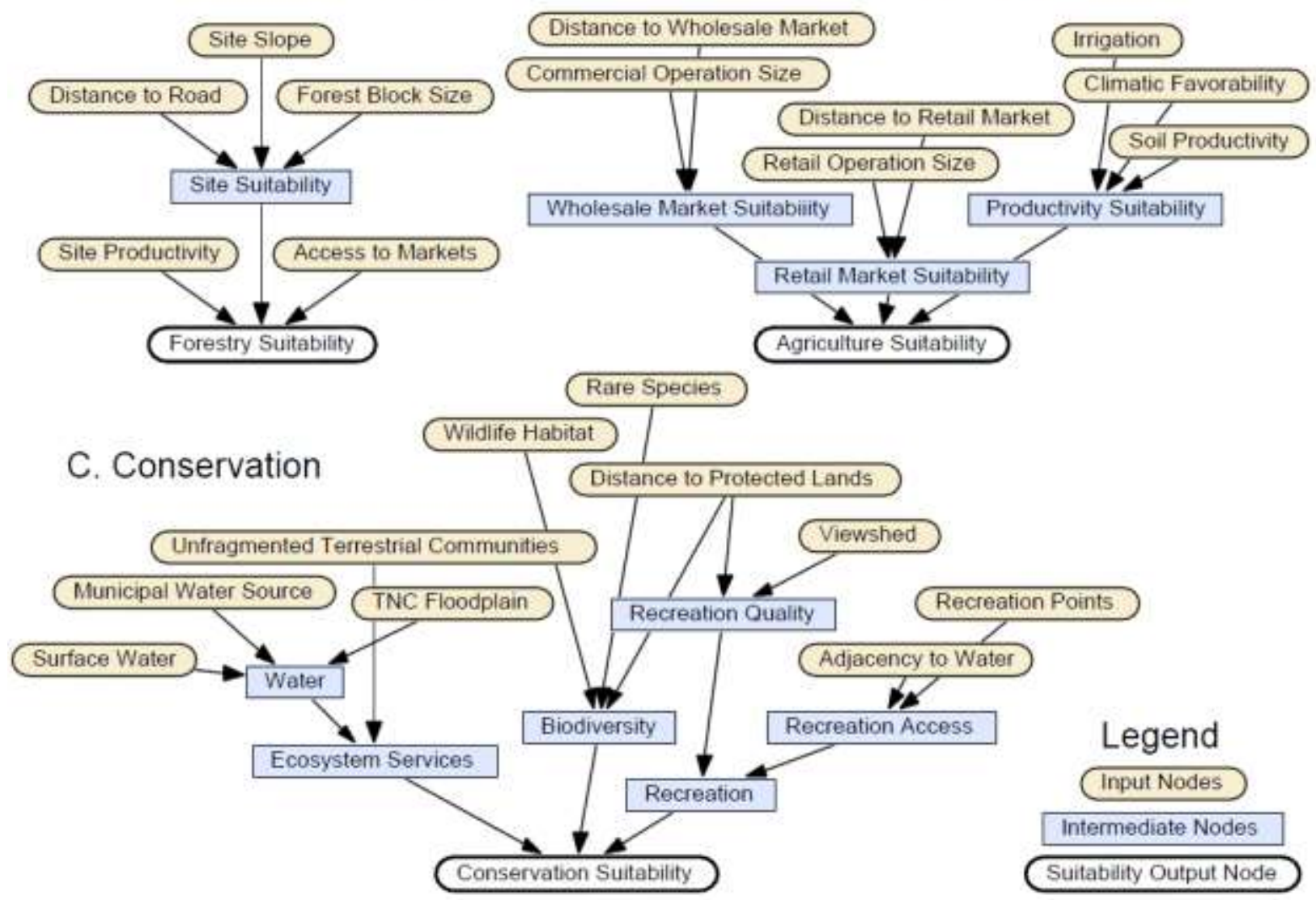
Figure 5 Bayesian network influence diagrams doe forestry, agriculture and conservation land uses in the Casco bay and Lower Androscoggin River Watershed (CBLA). Input nodes (yellow), intermediate nodes (blue), and the final outcome node (white) are shown for each of the (A) forestry, (B) agriculture, (C) conservation- local, and (D) conservation-landscape. (For interpretation of the references to color in this figure legend, the reader is referred to the final published version of this article.)

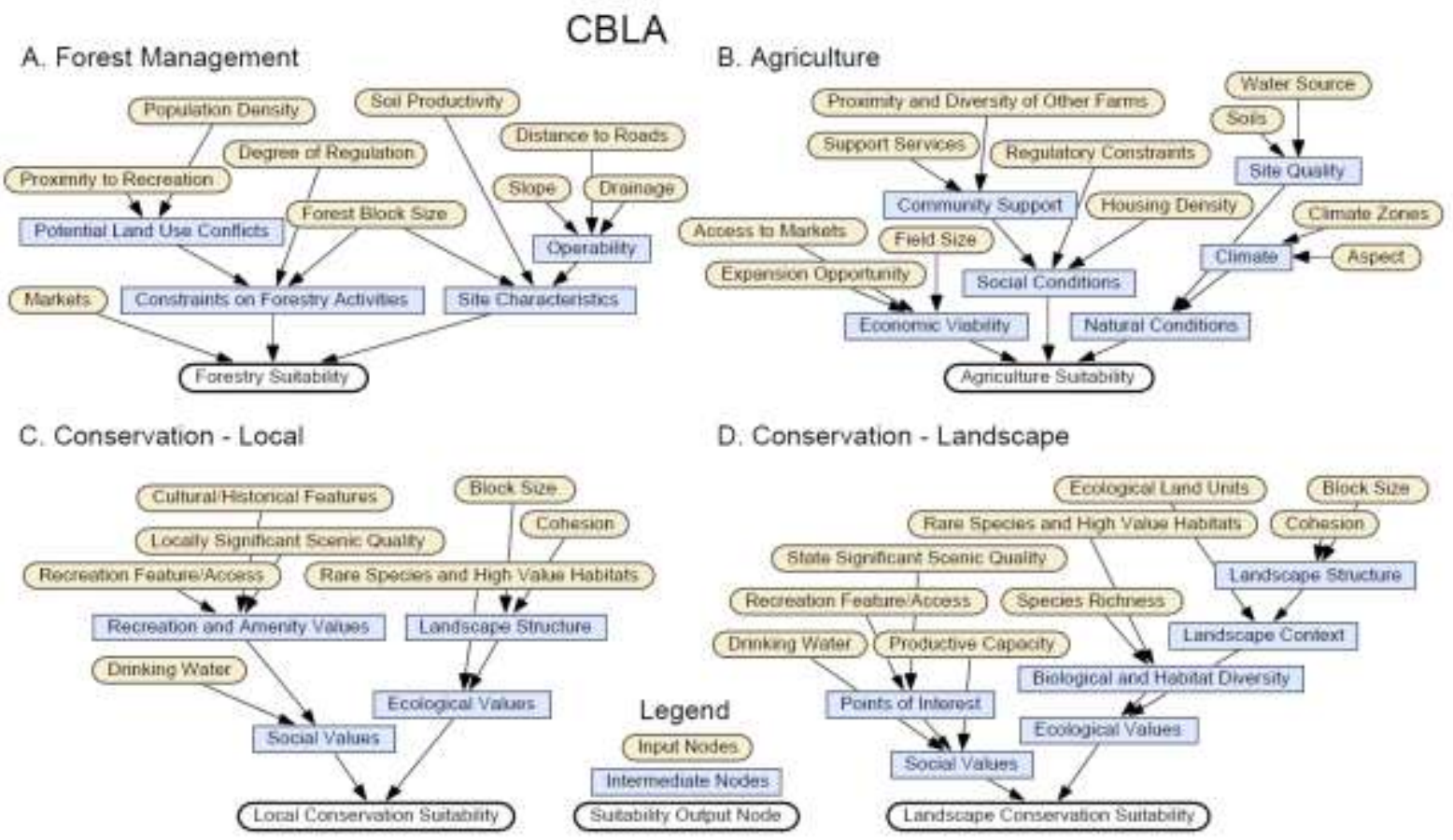


Table 2. For example, in a two-state node, a mean interval score ranging from 3.3 to 4.2 would correspond to a $25 \%$ high and $75 \%$ low percent probability distribution. We lacked sufficient sample size for a conclusive statistical test, but simple comparisons of the means between the stakeholder and researcher CPT responses indicated there were only minor differences between the two groups. Therefore we included both stakeholder and researcher ratings in the CPTs. Our system of converting interval scores to percent probability distributions spreads the probabilities across the possible state combinations and builds on the "pegging the corners" approach suggested by Marcot et al. (2006). It also allowed for some adjustments to reflect variation among stakeholder opinions.

\subsection{Processing the Bayesian Networks}

Using the relative importance of each input node, as defined in the CPT, we used the BN to estimate the probability of suitability for a given land use at a $30 \times 30 \mathrm{~m}$ pixel resolution. We developed a series of Python scripts to automate data aggregation, BN post-processing, mapping, and analysis processes. First, spatial data for each input node (see Figures 2 through 5) for each model (e.g., forestry, conservation, etc.) were classified according to the binary or ternary states structures for each node. For each BN, we combined the input rasters-one for each input node-to create a unique signature of combinations of pixel attributes occurring across the study areas. The attribute data for these rasters were then formatted as case files for Netica ${ }^{\circledR}$. BNs were then processed within Netica ${ }^{\circledR}$ using the input rasters and a specification "control" file unique to each land use BN. 
2.5 Mapping the Suitability

Next we joined the combined raster for each land use with the results of the BN to derive a probability of suitability for every pixel across each study area. For models where multiple submodels were created (i.e., residential, commercial, and amenity development in LPRW, residential and commercial development in CBLA, and local and landscape conservation in CBLA), we used the additive rule of probability for mutually exclusive occurrences to compute one composite score. We then extracted pixels that were known to be unavailable for a given land use. For example, areas that are already protected by either fee or easement conservation status were not available for development. Also, areas already developed and those classified as surface water by NLCD (Fry et al., 2011) were not considered available.

Final suitability scores for each pixel and land use category were classified into 10 equal intervals between 0 and 1 . For the models with composite suitability scores, we extended the score range to either 0 to 2 or 0 to 3, as applicable, and divided these ranges into 10 equal intervals. Suitability scores were further classified into high, medium, or low to correspond to the highest, middle, and lowest third of the possible scores for each suitability distribution (i.e., 0.67 to $1.0 ; 0.33$ to 0.67 ; and 0 to 0.33 ).

2.6 Model Evaluation 
Marcot (2012) provided guidance on evaluating performance and uncertainty of BNs using different metrics. Evaluating model performance is recognized as difficult for BNs (Aguilera et al., 2011; Barton et al., 2012; Marcot, 2012; Uusitalo, 2007) because when empirical data are unavailable, there is no way to compare model predictions to observed conditions. However, using experts and an iterative model development framework is an accepted evaluation approach for large causal probabilistic networks (Barton et al., 2012; Henriksen et al., 2007). In a meta-analysis of BNs used in environmental modeling, Aguilera et al. (2011) found that $44.8 \%$ of papers that use BNs for inference, as we do, included no validation at all. Of those papers that did provide some validation, the use of experts for validation was the most common method (13.2\% of the papers). In another $13.2 \%$ of the papers analyzed, a sensitivity analysis was presented in lieu of validation. Here, we evaluated our models using complexity and sensitivity analyses, and model performance was evaluated with stakeholder-based face validation.

First, we evaluated the relative complexity of each of our BNs based on metrics presented by Marcot (2012) , including the number of factors, links, node states, and total conditional probabilities for each BN. The total conditional probabilities (i.e., unique possible combinations of factor states) were computed after Marcot (2012). Second, we used the entropy reduction method within Netica ${ }^{\circledR}$ to assess the sensitivity of output suitabilities to each input factor (Marcot, 2012; Marcot et al., 2006). Entropy reduction is the most appropriate method when BNs use categorical variables. Third, we employed informal face validation (Qureshi et al., 1999; Sargent, 1991) techniques with our stakeholders. 
The absence of empirical data for land use suitability led us to explore alternative validation methods. We used iterative qualitative validation methods with our stakeholder groups throughout the duration of the project. At each stage of model development we elicited stakeholder feedback. The BNs were refined multiple times in at least two phases of stakeholder inspection during and subsequent to the focus groups. Node definitions (i.e., the binary and ternary state classifications) were negotiated generally according to consensus. After all model development, parameterization, and model processing were complete, we reconvened our stakeholders in two final focus groups-one for each watershed-where the stakeholders representing all four land uses met together. During these model evaluation sessions, we presented maps of suitability for all four land uses to the stakeholders and invited them to comment and critique the results of each model (i.e., not just the one land use to which the stakeholder contributed). We also asked stakeholders to suggest specific locations within the watershed for the group to focus on and to evaluate. Further refinements to the models were then made based on this feedback.

\section{RESULTS}

3.1 Suitability Factors and Structure of BN Models

\subsubsection{Development}


Stakeholders at the LPRW focus group decided to build three separate models to represent residential, commercial, and amenity-based development in the watershed, including 10, seven, and eight factors, respectively (Error! Reference source not found.). CBLA stakeholders identified eight factors each for their residential and commercial development models, forgoing a separate amenity development model (Error! Reference source not found.) since the group decided that it was not an important component of modeling overall development in that watershed.

\subsubsection{Conservation}

LPRW stakeholders identified 10 conservation suitability factors (Error! Reference source not found.), whereas CBLA stakeholders split conservation into two models (Error! Reference source not found.): a landscape-scale conservation model with nine factors that was similar to the independently constructed LPRW model and a local-scale conservation model with seven factors. While many of the factors in these two models appear similar, there are significant differences in the thresholds used to define states (Appendix). Moreover, four different representations of water-e.g., surface water, municipal water, floodplains, and adjacency to water-were included in the LPRW model, while CBLA stakeholders chose only to include drinking water. While each of the four water factors in the LPRW model represents a different use or aspect of water (Error! Reference source not found.), the multiple inclusions of waterrelated factors in the $\mathrm{BN}$ makes it an important element in determining overall conservation suitability. 


\subsubsection{Forestry}

Stakeholders identified five suitability factors for working forests in the LPRW, and nine for CBLA (Figures 4 and 5, respectively). The relatively simple model for LPRW reflects the sentiment expressed at the focus group that virtually all lands within the watershed were wellsuited for forestry. Stakeholders in the more urbanized CBLA region included two social factors as surrogates for potential conflicts that could limit forest operations: population density and proximity to recreational opportunities.

\subsubsection{Agriculture}

Stakeholders identified seven agriculture suitability factors in LPRW and 11 in CBLA (Figures 4 and 5, respectively). An important component of the LPRW model is the separation between retail and commercial agriculture factors. This distinction is absent in CBLA, where stakeholders instead included: (1) the proximity of farms to one another and to nearby farmable land as a surrogate for expansion opportunities; and (2) the nearby cultivation of diverse crops to help maintain diverse market opportunities and sustain supplier networks.

\subsection{Land Use Suitability}


Final suitability maps, with higher intensity colors indicating higher suitability, are presented in Figures 6 and 7 for each study area. Areas not considered available for each land use are shown in gray. For example, land already developed was excluded from the suitability analysis since one of our goals was to identify available areas highly suitable for each land use. In addition to this "already taken" category, areas under legal obligation to avoid certain land management practices (e.g., forestry or agriculture) were excluded. After accounting for these unavailable areas, the area modeled for each land use ranged from $81-91 \%$ of the total watershed (Table 3).

Evident in several of the suitability maps are underlying patterns created by one or more input nodes that have strong geographic patterns. For instance, in the LPRW agriculture map, the influence of water is evident in the long, linear features with high suitability (Figure 6). Similarly, the conservation map shows strong suitability patterns along water features, indicating the combined influence of several factors representing different functions of water (e.g., riparian habitat, aquatic species, flood control, drinking water, recreation access, etc.). In the agriculture map, the break between two climatic zones is clear in the southern portion of LPRW, where there is a strong suitability threshold between a cooler USDA hardiness zone and a warmer zone (Error! Reference source not found.).

In both the CBLA and LPRW development maps, there are strong visual trends of high suitability near existing development, including urban centers and road infrastructure (Figures 6 and 7). In the development sub-models, particularly in LPRW, commercial and residential trends 
were similar. The individual BNs are shown in Figures 2 and 3, but these suitability scores are aggregated in Figures 6 and 7. The residential model was more heavily influenced by site-level factors (e.g., soil and slope), whereas commercial suitability was heavily influenced by transportation and other market-related factors (e.g., roads and utilities).

In contrast to the residential and commercial sub-models, amenity development showed more isolated and distributed patches of high suitability, particularly near water bodies. In the forestry map, there are less-obvious visual patterns, although an apparent inverse relationship with distance from development trend is suggested in both watersheds. While this was not directly specified in the model, distance to roads and forest block size likely influence this pattern.

The amount of available area that was predicted to be highly suitable (i.e., top one-third of range of possible scores) varied from only $3 \%$ for agriculture in CBLA, to $99 \%$ for forestry in LPRW (Table 3). The largest difference between the watersheds was high-suitability for development, which comprises $5 \%$ of the available area in LPRW and $38 \%$ of CBLA - a nearly eight-fold difference. Area highly suitable for forestry in CBLA comprises $84 \%$ of the available area, which is $15 \%$ less than that of LPRW.

3.3Model Evaluation 


\subsubsection{BN Complexity Analysis}

Model complexity measures are presented in Table 4. LPRW models included 47 factors while CBLA included 52 factors. Each of the 99 total factors was represented in the models by empirical GIS data, with an average across both watersheds of 8.3 factors per model. As Marcot (2012) explains, models with the same number of factors and links can be structured differently, resulting in more complex or less complex models despite reliance on identical inputs. Our analysis showed that the basic numbers of factors and links were similar between the study areas, yet CBLA had 40\% greater complexity, with an average of 192.5 conditional probabilities per model compared to only 137.5 in LPRW. This implies that the CBLA models tended to have more complex structures than those in LPRW.

Comparing our models to those developed solely by the research team of McCloskey et al. (2011), two members of which served on both research teams, shows our models co-developed with stakeholders were more complex. For example, our LPRW development model consists of three sub-models with 10, 7, and 8 nodes, for a total of 25. In contrast, McCloskey et al. (2011) used a single development model for the same watershed with just six nodes. Similarly, our conservation model had 10 nodes compared to five in McCloskey et al.

\subsubsection{BN Sensitivity Analysis}


The relative sensitivity for each input and intermediate node within each land use model is presented in Table 5. The forestry model was nearly twice as sensitive to access to markets as it was to site productivity, the next-most important factor. In the conservation model, which has the most number of inputs of any of the models, the top three factors-distance to protected areas, unfragmented terrestrial communities, and rare species-exert the most leverage in the model. Among intermediate nodes in this model, the recreation group had nearly $43 \%$ and $59 \%$ higher leverages than did biodiversity and ecosystem services groupings. For commercial development, infrastructure (i.e., electricity and broadband access) had eight-fold higher leverage than the next highest node, ability to distribute products. The residential model had more uniform sensitivity across its 10 nodes, but the site group had three-fold the leverage of the next-most important group, entry costs.

\subsubsection{Suitability Validation}

Stakeholders were generally in agreement with the suitability results. When we closely examined several case studies of parcels or regions familiar to one or more stakeholders, the suitability results matched stakeholder expectations. In an example of independent verification, a local media outlet reported on a large farm in LPRW that had been identified by a regional agricultural land trust as a high priority for farmland conservation. Independently, our models identified a large portion of that parcel as highly suitable for agriculture, and a subset as highly suitable for both conservation and development. 
Stakeholder disagreements with model results generally fell into two categories: (1) stakeholder-identified errors, omissions, or misinterpretations of stakeholder input in model specification or state classifications; and (2) stakeholder-expressed dissatisfaction with model outputs that did not match their perceptions. For example, in reviewing mapped outputs for LPRW, there was some confusion among stakeholders about the intent of the property tax node. When first identified during the BN development process, stakeholders-including actual developers, realtors, and other business experts-defined property tax as inversely related to residential suitability (i.e., towns with lower property taxes were more desirable). The CPT surveys corroborated this view. However, towns with higher property tax rates typically have more desirable features (e.g., better K-12 education, transportation infrastructure, etc.), in effect counteracting the property tax factor in the model. Because of the flexibility of BNs, we were able to easily compare results with the tax factor expressed negatively and positively. After comparing the differences, the stakeholders and the research team decided to consider lower taxes as the more desirable condition.

An example where outputs did not match stakeholders' expectations was the LPRW conservation model. There, stakeholders were concerned that model outputs did not sufficiently prioritize buffer areas around existing core protected lands. The research team verified that the CPTs elicited from stakeholder surveys were accurate. While stakeholders had identified buffer areas as important for conservation, the aforementioned heavy leverage of water features in the conservation model likely contributed to the relatively low suitability of buffer areas in the final model outputs. In another example, CBLA forestry stakeholders were 
concerned about the high level of influence exerted initially by the forest products market access node. The research team then consulted independent, external stakeholders to help refine the thresholds used to parameterize the high-quality forest product markets factor, which resulted in greater differentiation in suitability across the watershed, although the leverage of the node in the $\mathrm{BN}$ remained high (Table 5).

\section{DISCUSSION}

Key insights from our research fall into two primary categories related to: (1) stakeholder engagement in a land use modeling framework; and (2) the application of BNs for estimating land use suitability. We recognize that each category by itself is subject to entire bodies of literature, but it is through the integration of the two that we sought to advance modeling with our work.

\subsection{Stakeholder Engagement}

\subsubsection{Stakeholder participation}

It was a challenge to engage stakeholders in a meaningful way throughout the several months that each group was active. The level of stakeholder participation at each stage (i.e., model development, parameterization, validation) varied considerably among the land use focus groups and the two study areas. Unfortunately, we cannot evaluate the effects of having 
different stakeholders contribute at different stages of the process. For instance, if stakeholders 1 through 5 helped design the conceptual model and BN, but stakeholders 3 through 8 (i.e., there was only small overlap in perspectives) were present for parameterization, did that compromise our stakeholder input or make it more robust?

After our validation workshops for each study area, each of which included stakeholders from all four land uses, we queried stakeholders and researchers on their thoughts about how well the models reflected their values and expert knowledge. We found that the stakeholders believed that the model reflected their opinions more than those of the researchers - a view similarly expressed by the researchers. We were encouraged by the level of enthusiasm from the stakeholders who had stayed active in the process by participating in later focus groups. Many stakeholders felt that participating in the process-especially the final two focus groups that brought together stakeholders from the different land uses-expanded their perspectives and would improve their professional work.

\subsubsection{Sensitivity of model output to discretization of stakeholder knowledge}

Our modeling relied on stakeholders to identify discrete thresholds that could be used to convert continuous factors within BNs into discrete suitability categories (e.g., adjacent, near, and far thresholds specifying distances from roads ideal for building housing developments) (Krueger et al., 2012). In each case, we attempted to reach consensus among stakeholders, recognizing that these demarcations are subjective. In some cases, we believe this 
discretization led to conflation between model sensitivity and utility. For instance, although agriculture stakeholders in CBLA gave a high importance ranking to USDA climate zones-which themselves are discrete representations of continuous climate data-there was very little differentiation in the zones themselves within CBLA; thus the result shows little separation of suitability across the study area.

Understanding the implications of threshold choices as they propagate through the BN structure (i.e., CPTs and final suitability scores) is an important aspect of the modeling process. Since this uncertainty results from the discretization of continuous factors and is sensitive to the specific thresholds chosen by the stakeholders, we spent considerable time debating individual thresholds with the stakeholders throughout model development. In some cases, after beta suitability models were shown to stakeholders, we revised thresholds to reflect more accurately the stakeholders' opinions. In the case of the access to markets node in the LPRW forestry model, even numerous permutations of thresholds yielded no difference in the overall suitability, even though that node had the highest leverage in the model.

\subsubsection{Validating models based on stakeholder opinion}

Validating land use models is an important step in assessing their plausibility and relevance. Yet standard validation methods that compare model predictions to known observations are illsuited for suitability analyses that rely on expert opinion of factors of change (Aspinall, 2004; Celio et al., 2012). In addition to the lack of validation datasets for this type of research, 
validation for BNs is problematic for at least two reasons. First, stakeholder opinion is not static and may change through time, responding to exogenous and endogenous socio-economic factors. In a land use suitability model developed to project land use under alternative scenarios, this can be especially problematic. It can also be an advantage, however. When economic shocks occur-such as the 2008 economic crisis and housing collapse in the U.S.empirical models may conflate short-term trends with future consumer behavior, whereas stakeholder-driven models focus on the drivers of change rather than the specific short-term changes.

A second obstacle to model validation is the fact that our BN outputs portray the probability of suitability, and do not reflect current or future demand for particular land uses. For instance, our combined development model indicated that vastly more area is highly suitable for development than is required under past or likely future market conditions. Furthermore, land use decisions are influenced by a host of other intrinsic and extrinsic factors that are not generalizable for modeling purposes. For instance, the willingness of a property owner to sell is certainly a greater predictor of change for a given parcel than any factor included in our model, yet this information is not readily available and is too spatially and temporally dynamic to include in a land use model. Also, probabilistic suitability can be undermined by other behaviors. For example, it is common practice in forest management to overcome certain poor site characteristics - when the market forces make an operation profitable-by harvesting during winter conditions when the ground is frozen. 
As indicated in the results, we evaluated and attempted to validate the models with multiple approaches. Ultimately, however, the validity of a land use model is perhaps best confirmed or denied through testing of the model by practicing planners, decision-makers, and researchers. To the extent that further testing demonstrates that our model provides a systematic framework for integrated analysis of competing land uses and contributes to more strategic and holistic planning and policy decisions, it will be possible to make more definitive statements about the validity of this BN model.

4.2 Application of BN for Land Use Suitability

\subsubsection{Differences in scale between socio-economic and biophysical factors}

A primary goal of our research was to better understand the factors driving suitability for different types of land uses. Here, it is important to consider not only the actual mechanisms, but also the scale at which these occur. Our modeling showed that biophysical factors (e.g., soil quality, water type and function, contiguous forest cover, species habitats, etc.) tended to act on the system at relatively small geographic scales compared with socio-economic factors (e.g., zoning ordinances, development infrastructure, existing metrics of urbanization, community amenities, etc.). In short, there was more spatial homogeneity at the municipal scale in socioeconomic factors, likely as a result of jurisdictional boundaries and existing policy and institutions enacted at those levels. Factors such as educational opportunities and property tax rates do not vary substantially below the municipality level. Conversely, there is great spatial 
heterogeneity in biophysical factors since these factors tend to be based on environmental gradients, biological communities, or geological substrates, and are typically mapped at a $30 \mathrm{~m}$ grain size.

Our results identified that many municipal-level social and economic factors exerted greater influence over land use suitability measures than did sub-municipal and finer-resolution biophysical factors. For example, the high sensitivity of the development model to zoning in the CBLA (a three-fold higher leverage than the next-most important factor; see Table 5) is clearly evident in the nearly binary suitability results at the municipal level shown in Error! Reference source not found.. In comparison, the LPRW development model shows a network-like pattern of suitability, which results from high leverage exerted by transportation and infrastructure factors (Error! Reference source not found. and Table 5). This suggests that the development models (and the experiences and opinions of the stakeholders who built them) weight municipal-level factors more strongly than fine-scale biophysical factors.

\subsubsection{Model parsimony versus model utility}

There is conflict between parsimonious BNs and the ability of a BN to yield useful inferences via a wide separation across the spectrum of suitability. Balancing these two goals has consequences for model uncertainty and its utility for decision-makers. For example, the LPRW forestry model utilizes only five factors, while the CBLA model includes nine. Despite its attractive parsimony, the LPRW model provides scant spatial differentiation in suitability (Error! 
Reference source not found.). Simply comparing the results for the two watersheds would indicate that the LPRW is inherently better-suited for forestry, yet this result is largely derived from the lower variability embodied in the BN's structure, particularly as a function of the aforementioned access to markets node. Gray et al. (2012) found similar decreases in precision to be a general result of integrating stakeholder knowledge - a finding we do not share. Instead, our result was likely a case where stakeholder knowledge provided imprecise model specification. For example, the LPRW agriculture model is, by one measure, half as complex as the CBLA agriculture model (i.e., total number of conditional probabilities; see Table 4), yet provides greater discrimination between high suitability and the lower categories of suitability (Error! Reference source not found.).

\subsubsection{Informing land use decisions}

The ultimate goal of land use modeling is to empower decision-makers to make more informed decisions. Since one of the primary motivations for our research was to develop land use suitability models to inform stakeholder decision-making, it is important that the models: (1) reflect stakeholder input; (2) are understandable by those involved in the project and the extended stakeholders who are likely to use project outputs; and (3) provide data to support or influence the perceptions of regional decision makers (Celio et al., 2012). Therefore, models should be vetted not just for their scientific rigor, but also for their ability to provide inferences to decision-makers. While some factors in our models failed to provide strong differentiation in suitability, they do allow stakeholders-both those who participated in the process and those 
who will use the results - to visualize the impact of many biophysical and socioeconomic factors affecting land use suitability.

\section{CONCLUSION}

Our goal was to develop a comprehensive stakeholder-driven modeling framework that could identify and model complex socio-economic and biophysical processes across multiple land uses over two large watersheds. Though our models used 99 empirical datasets for the individual factors of suitability, we had to rely heavily on stakeholder opinion to discretize the data and to identify the relationships between the factors. While stakeholder expertise was invaluable, our inability to adequately calibrate and validate model performance against known land use suitability places some limits on the models' utility for prediction. On the other hand, our models have high credibility among participating stakeholders as well as others who value stakeholder input. Given that these models are intended to aid in decision-making, we accept the above trade-offs in exchange for high stakeholder credibility and coverage of nearly 2 million hectares of land use suitability. We also note that our modeling framework provides for an iterative process of adaptive modification that allows for the incorporation of improved information over time. Furthermore, our inclusion of stakeholders in our modeling process was a long-term investment intended to improve the link between land use modeling and decisionmaking by integrating local expert knowledge into land use modeling. 
At the outset, we envisioned BNs as a flexible modeling approach that could rapidly substitute stakeholder knowledge for unobservable data. This was true to some extent, but including input from stakeholders caused the models to be substantially more complex than originally anticipated. The differences in model complexity of: (1) our models compared with the preliminary models developed by McCloskey et al. (2011); and (2) our models in LPRW compared to those in CBLA, suggest that the modeling approach and complexity are highly tailored to the modeling team - which in our case included stakeholders - and perhaps particularly the size of the group. The detailed assumptions required for model parameterization-largely defined by consensus-are highly influential as well. Though these added complexities introduce many challenges to modeling, they may better reflect the real complexity of the system being modeled, thus making it more relevant for making land use decisions. So, while the assumptions of a specific model may not always be transferable, the modeling approach is. These BNs are easily customized for different regions and stakeholder groups, and we expect that through repeated applications the model structures themselves may converge towards some standard "best-fit" models.

We are currently developing a web-based, open-access planning tool based on these suitability models. The Maine Futures Community Mapper (MFCM;

www.MaineLandUseFutures.org) combines the suitability results presented here with two associated modeling projects, which are in preparation as stand-alone publications: (1) a conflict and opportunities analysis that identifies both areas of high conservation priority (i.e., based on expected threat from competing uses) and areas with high development suitability 
that do not impinge on high suitability conservation or natural resource management areas; and (2) an alternative futures analysis that models stakeholder-derived scenarios of future land use patterns, based on the current land use suitabilities developed here. The MFCM is a partnership between universities, NGOs, the private sector, and government agencies that will provide a strategic land use planning decision support tool for professional planners, community volunteer committees, and regulatory agencies.

Applied tools that blend scientific rigor with stakeholder engagement are needed to bridge the divide between science and on-the-ground land use planning. Furthermore, to inform planning processes that seek to avoid undesirable land use conflicts, models must take into account both conservation and economic development needs. The flexible modeling framework developed here addresses both of these needs, but leaves ample room for improvement. Scientists and practitioners can work across boundaries to develop solutions if they are willing to accept some trade-offs. We have identified several of these trade-offs, and encourage other researchers to take an adaptive management approach to modeling where both stakeholder engagement and modeling methods are refined simultaneously. We also encourage the continued integration of conservation planning with other land use models to identify win-win solutions that have social and political feasibility. 


\section{ACKNOWLEDGEMENTS}

This research was conducted as part of the Sustainability Solutions Initiative, supported by National Science Foundation award EPS-0904155 to Maine EPSCoR at the University of Maine, the University of Maine's Center for Research on Sustainable Forests, the Maine Agricultural and Forest Experiment Station (Publication Number 3356) and McIntire-Stennis Grant \#MEO-M7-00510-13from the USDA National Institute of Food \& Agriculture. We are grateful for the expertise and commitment that more than 75 stakeholders from Maine lent to this project. Jeremy Wilson and Eric Gallandt of the University of Maine and David Owen of the University of Maine School of Law contributed to the development of this research and participated in the focus groups. We thank Andy Cutko of the Maine Natural Areas Program, Steve Walker of the Maine Inland Fisheries and Wildlife, and Josh Royte of The Nature Conservancy for access to numerous ecological datasets; Dan McConville of the James W. Sewall Company for assistance with forest products markets; Judy Colby-George of Spatial Alternatives and Liana James of the University of Maine School of Law for assistance with zoning data; and Stephen Engle and Jean Luc Theriault of the Center for Community GIS and Jill Tremblay for technical GIS support. 


\section{LITERATURE CITED}

Aguilera, P.A., Fernández, A., Fernández, R., Rumí, R., Salmerón, A., 2011. Bayesian networks in environmental modelling. Environ. Model. Softw. 26, 1376-1388.

Anderson, M.G., Clark, M., Sheldon, A.O., 2012. Resilient sites for terrestrial conservation in the Northeast and Mid-Atlantic Region. The Nature Conservancy, Eastern Conservation Science. p. 289.

Aspinall, R., 2004. Modelling land use change with generalized linear models--a multi-model analysis of change between 1860 and 2000 in Gallatin Valley, Montana. J. Environ. Manage. 72, 91-103.

Baker, J.P., Hulse, D.W., Gregory, S.V., White, D., Van Sickle, J., Berger, P.A., Dole, D., Schumaker, N.H., 2004. Alternative futures for the Willamette River Basin, Oregon. Ecol. Appl. 14, 313-324.

Barton, D.N., Kuikka, S., Varis, O., Uusitalo, L., Henriksen, H.J., Borsuk, M., de la Hera, A., Farmani, R., Johnson, S., Linnell, J.D.C., 2012. Bayesian networks in environmental and resource management. Integr. Environ. Assess. Manag. 8, 418-29.

Beier, P., Spencer, W., Baldwin, R.F., McRae, B.H., 2011. Toward best practices for developing regional connectivity maps. Conserv. Biol. 25, 879-92.

te Brömmelstroet, M., 2009. The relevance of research in planning support systems: a response to Janssen et al. Environ. Plan. B, Plan. Des. 36, 4-7.

Brookings Institution, 2006. , Charting Maine's future: An action plan for promoting sustainable prosperity and quality places. Metropolitan Policy Program, Washington, DC. p. 144.

Cash, D.W., Clark, W.C., Alcock, F., Dickson, N.M., Eckley, N., Guston, D.H., Jager, J., Mitchell, R.B., 2003. Knowledge systems for sustainable development. Proc. Natl. Acad. Sci. USA. 100, 8086-8091.

Celio, E., Brunner, S.H., Grêt-regamey, A., 2012. Participatory land use modeling with Bayesian networks : a focus on subjective validation. Proc. of the 2012 International Congress on Environmental Modelling and Software. Leipzip, Germany.

Charniak, E., 1991. Bayesian networks without tears. Al Mag. 12, 50-63.

Downs, A., 2005. Smart growth: why we discuss it more than we do it. J. Am. Plan. Assoc. 71, 367-378.

Fry, J., Xian, G., Jin, S., Dewitz, J., Horner, C., Yang, L., Barnes, C., Herald, N., Wickham, J., 2011. National land cover database (NLCD). Photogramm. Eng. Remote Sens. 77, 858-864.

Gray, S., Chan, A., Clark, D., Jordan, R., 2012. Modeling the integration of stakeholder knowledge in social-ecological decision-making: Benefits and limitations to knowledge diversity. Ecol. Modell. 229, 88-96.

Haines-Young, R., 2011. Exploring ecosystem service issues across diverse knowledge domains using Bayesian belief networks. Prog. Phys. Geogr. 35, 681-699. 
Henriksen, H., Rasmussen, P., Brandt, G., Vonbulow, D., Jensen, F., 2007. Public participation modelling using Bayesian networks in management of groundwater contamination. Environ. Model. Softw. 22, 1101-1113.

Howes, A.L., Maron, M., McAlpine, C.A., 2010. Bayesian networks and adaptive management of wildlife. Conserv. Biol. 24, 974-983.

Hulse, D.W., Ranscomb, A.B., Payne, S.G., 2004. Envisioning alternatives: Using citizen guidance to map future land and water use. Ecol. Appl. 14, 325-341.

Knight, A.T., Cowling, R.M., Rouget, M., Balmford, A., Lombard, A.T., Campbell, B.M., 2008. Knowing but not doing: selecting priority conservation areas and the researchimplementation gap. Conserv. Biol. 22, 610-617.

Kocabas, V., Dragicevic, S., 2007. Enhancing a GIS cellular automata model of land use change : Bayesian networks, influence diagrams and causality. Trans. GIS 11, 681-702.

Kok, K., Veldkamp, A, 2001. Evaluating impact of spatial scales on land use pattern analysis in Central America. Agric. Ecosyst. Environ. 85, 205-221.

Krueger, T., Page, T., Hubacek, K., Smith, L., Hiscock, K., 2012. The role of expert opinion in environmental modelling. Environ. Model. Softw. 36, 4-18.

Lilieholm, R.J., Irland, L.C., Hagan, J.M., 2010. Changing socio-economic conditions for private woodland protection. In: Trombulak, S.C., Baldwin, R.F., editors. Landscape-scale conservation planning. Springer, New York, pp. 67-98.

Malczewski, J., 2004. GIS-based land-use suitability analysis: a critical overview. Prog. Plann. 62, 3-65.

Marcot, B.G., 2012. Metrics for evaluating performance and uncertainty of Bayesian network models. Ecol. Modell. 230, 50-62.

Marcot, B.G., Steventon, J.D., Sutherland, G.D., McCann, R.K., 2006. Guidelines for developing and updating Bayesian belief networks applied to ecological modeling and conservation. Can. J. For. Res. 36, 3063-3074.

Margules, C.R., Pressey, R.L., 2000. Systematic conservation planning. Nature 405, 243-253.

Martin, T.G., Burgman, M. a, Fidler, F., Kuhnert, P.M., Low-Choy, S., McBride, M., Mengersen, K., 2012. Eliciting expert knowledge in conservation science. Conserv. Biol. 26, 29-38.

McCloskey, J.T., Lilieholm, R.J., Cronan, C., 2011. Using Bayesian belief networks to identify potential compatibilities and conflicts between development and landscape conservation. Landsc. Urban Plan. 101, 190-203.

McDonald, R.I., 2009. The promise and pitfalls of systematic conservation planning. Proc. Natl. Acad. Sci. USA. 106, 15101-2.

Miller, J.R., Snyder, S.A., Skibbe, A.M., Haight, R.G., 2009. Prioritizing conservation targets in a rapidly urbanizing landscape. Landsc. Urban Plan. 93, 123-131.

Newburn, D., Reed, S., Berck, P., Merenlender, A., 2005. Economics and land-use change in prioritizing private land conservation. Conserv. Biol. 19, 1411-1420. 
O'Hagan, A., 2012. Probabilistic uncertainty specification: Overview, elaboration techniques and their application to a mechanistic model of carbon flux. Environ. Model. Softw. 36, 35-48.

Parker, D., Manson, S., Janssen, M., Hoffmann, M., Deadman, P., 2003. Multi-agent systems for the simulation of land-use and land-cover change: A review. Ann. Assoc. Am. Geogr. 93, 314337.

Price, J., Silbernagel, J., Miller, N., Swaty, R., White, M., Nixon, K., 2012. Eliciting expert knowledge to inform landscape modeling of conservation scenarios. Ecol. Modell. 229, 7687.

Qureshi, M.E., Harrison, S.R., Wegener, M.K., 1999. Validation of multicriteria analysis models. Agric. Systems 62, 105-116.

Sargent, R.G., 1991. Simulation model verification and validation. In: Nelson, B.L., Kelton, W.D., Clark, G.M., editors. Proceedings of the 1991 Winter Simulation Conference. pp. 37-47.

Scott, A., 2011. Focusing in on focus groups: Effective participative tools or cheap fixes for land use policy? L. Use Policy 28, 684-694.

Smith, C.S., Howes, A.L., Price, B., McAlpine, C.A., 2007. Using a Bayesian belief network to predict suitable habitat of an endangered mammal - The Julia Creek dunnart (Sminthopsis douglasi). Biol. Conserv. 139, 333-347.

Spiegelhalter, D.J., Dawid, A.P., Lauritzen, S.L., Cowell, R.G., 2013. Bayesian analysis in expert systems. Statist. Sci. 8, 219-247.

Stein, S.M., McRoberts, R.E., Alig, R.J., Nelson, M.D., Theobald, D.M., Eley, M., Dechter, M., Carr, M., 2005. Forests on the edge: Housing development on America's private forests, General Technical Report PNW-GTR-636. USDA Forest Service, Pacific Northwest Research Station. Portland, OR. p. 16.

Stein, S.M., McRoberts, R.E., Mahal, L.G., Carr, M.A., Alig, R.J., Comas, S.J., Theobald, D.M., Cundiff, A., 2009. Private forests, public benefits : Increased housing density and other pressures on private forest contributions. General Technical Report PNW-GTR-795. USDA Forest Service, Pacific Northwest Research Station. Portland, OR. p. 74.

Steiner, F.R., 1990. The living landscape: An ecological approach to landscape planning. New York: McGraw-Hill.

Swetnam, R.D., Fisher, B., Mbilinyi, B.P., Munishi, P.K.T., Willcock, S., Ricketts, T., Mwakalila, S., Balmford, A, Burgess, N.D., Marshall, A.R., Lewis, S.L., 2011. Mapping socio-economic scenarios of land cover change: a GIS method to enable ecosystem service modelling. J. Environ. Manage. 92, 563-574.

Turner, B.L., Lambin, E.F., Reenberg, A., 2007. The emergence of land change science for global environmental change and sustainability. Proc. Natl. Acad. Sci. U. S. A. 104, 20666-20671.

United States Census, 2010. MAF/TIGER database. Retrieved August 8, 2013 from http://www.census.gov/geo/maps-data/data/tiger-data.html. 
Uusitalo, L., 2007. Advantages and challenges of Bayesian networks in environmental modelling. Ecol. Modell. 203, 312-318.

Varkey, D.A., Pitcher, T.J., McAllister, M.K., Sumaila, R.S., 2013. Bayesian decision-network modeling of multiple stakeholders for reef ecosystem restoration in the Coral Triangle. Conserv. Biol. 27, 459-469.

Verburg, P.H., Soepboer, W., Veldkamp, A., Limpiada, R., Espaldon, V., Mastura, S.S.A., 2002. Modeling the spatial dynamics of regional land use: the CLUE-S model. Environ. Manage. 30, 391-405.

Voinov, A., Bousquet, F., 2010. Modelling with stakeholders. Environ. Model. Softw. 25, 12681281.

White, E.M., Alig, R.J., Stein, S.M., Mahal, L.G., Theobald, D.M., 2009. A sensitivity analysis of "Forests on the edge: housing development on America's private forests." General Technical Report PNW-GTR-792. USDA Forest Service, Pacific Northwest Research Station. Portland, OR. p. 44. 


\section{FIGURES}

Figure 1 Location of the Lower Penobscot River Watershed (LPRW) and Casco Bay and Lower Androscoggin watershed (CBLA) study areas within Maine.
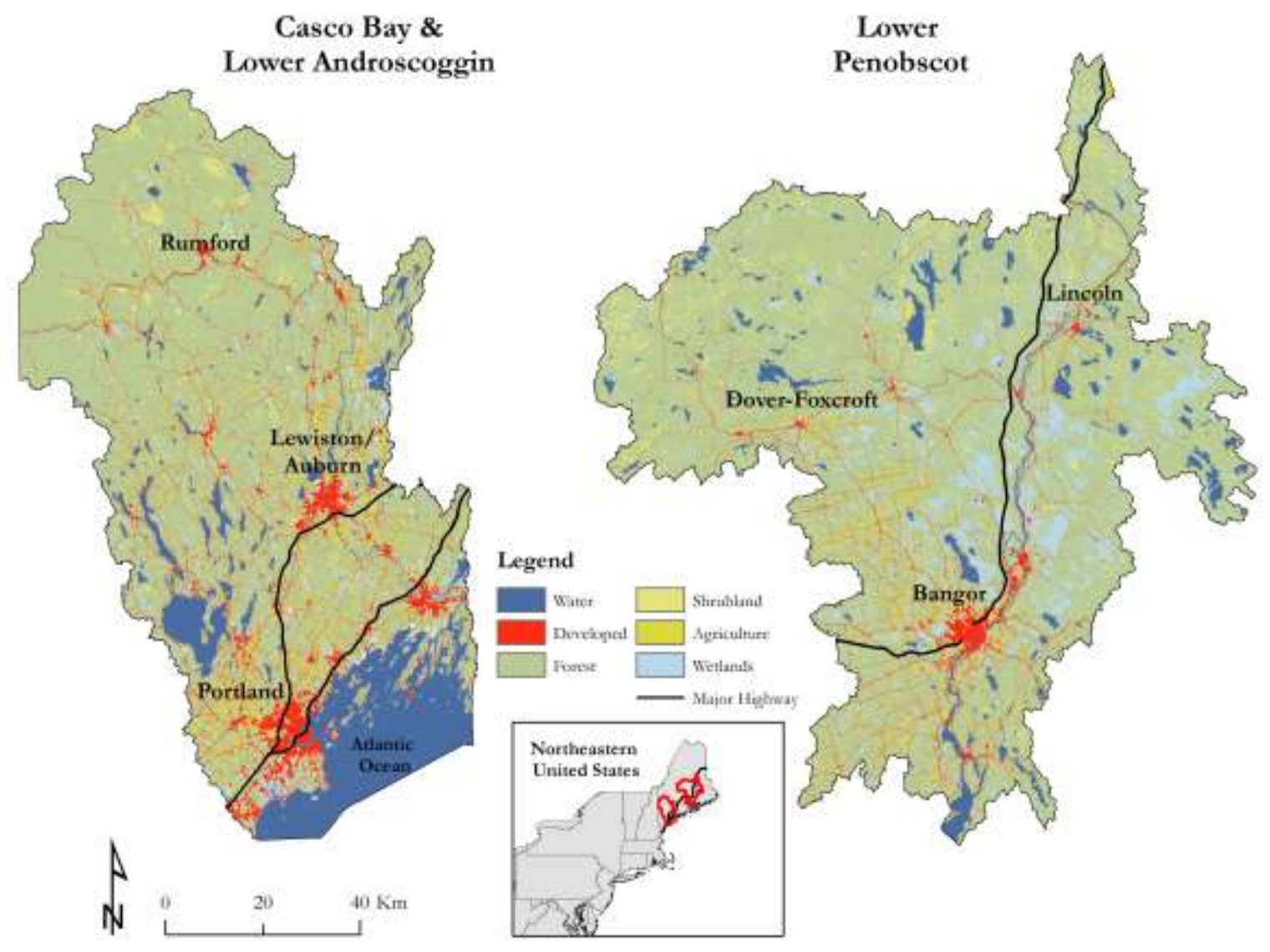
Table 1. Five stakeholder focus groups were convened for each study area (Lower Penobscot River Watershed-LPRW; Casco Bay and Lower Androscoggin Watershed-CBLA), including one combined event including participants from each of the previous events.

\begin{tabular}{|c|c|c|c|c|c|c|c|c|}
\hline \multirow[b]{3}{*}{ Land Use Group } & \multicolumn{4}{|c|}{$\underline{\mathrm{LPRW}}$} & \multicolumn{4}{|c|}{$\underline{\mathrm{CBLA}}$} \\
\hline & \multirow[b]{2}{*}{ Date } & \multirow{2}{*}{$\begin{array}{c}\text { Focus Group } \\
\text { Participants }\end{array}$} & \multicolumn{2}{|c|}{ CPT Survey Respondants } & \multirow[b]{2}{*}{ Date } & \multirow{2}{*}{$\begin{array}{c}\text { Focus Group } \\
\text { Participants }\end{array}$} & \multicolumn{2}{|c|}{ CPT Survey Respondants } \\
\hline & & & Stakeholders & Researchers* & & & Stakeholders & Researchers* \\
\hline Conservation & June 2010 & 5 & 3 & 5 & March 2012 & 8 & 6 & 4 \\
\hline Forestry & June 2010 & 8 & 5 & 5 & April 2012 & 7 & 6 & 5 \\
\hline Agriculture & September 2010 & 5 & 4 & 5 & April 2012 & 9 & 10 & 5 \\
\hline Development & March 2011 & 6 & 4 & 5 & March 2012 & 7 & 6 & 4 \\
\hline All-Stakeholder Focus Group ${ }^{a}$ & November 2011 & 10 & & & November 2012 & 11 & & \\
\hline Tota & & 24 & 16 & 5 & & 31 & 28 & 5 \\
\hline
\end{tabular}

a These values are excluded from the total to avoid double-counting. 
Figure 2 Bayesian network influence diagrams for development land used in the lower Penobscot River Watershed (LPRW). Input nodes (yellow rounded boxes), intermediate nodes (blue rectangle boxes), and the final outcome node (white rounded boxes), are shown for each of the $(A)$ residential, $(B)$ commercial development, and (C) amenity development suitability models.

\section{A. Residential Development LPRW}

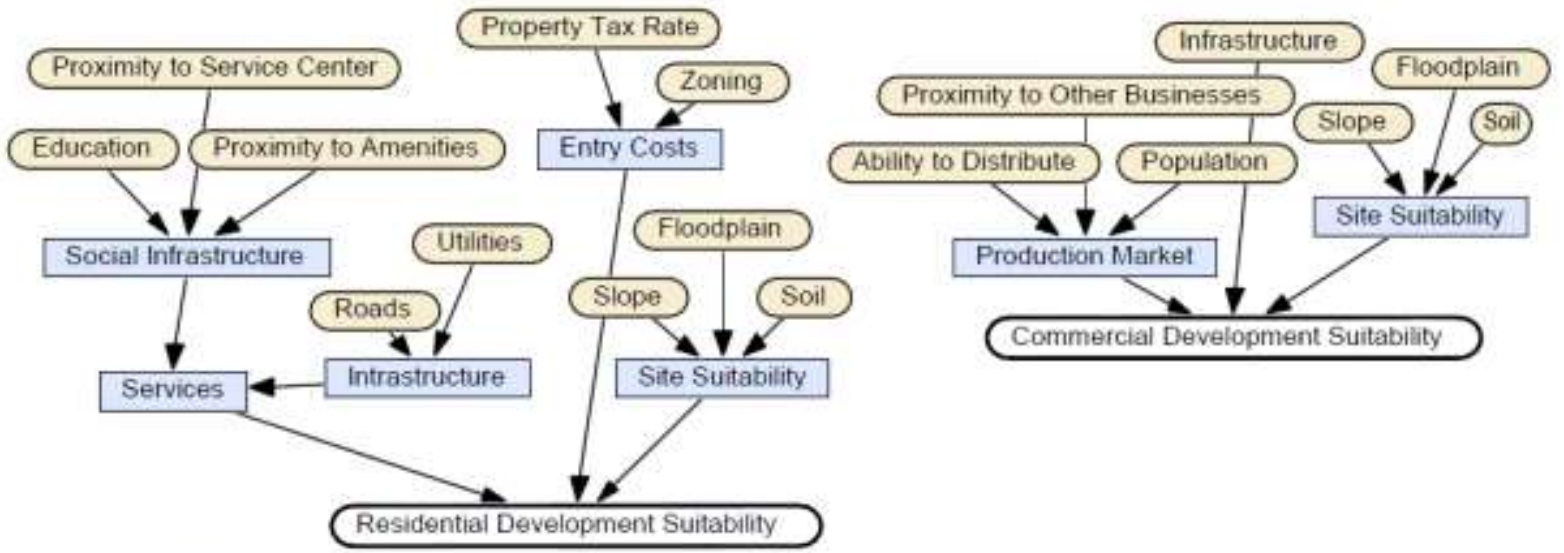

C. Amenity Development

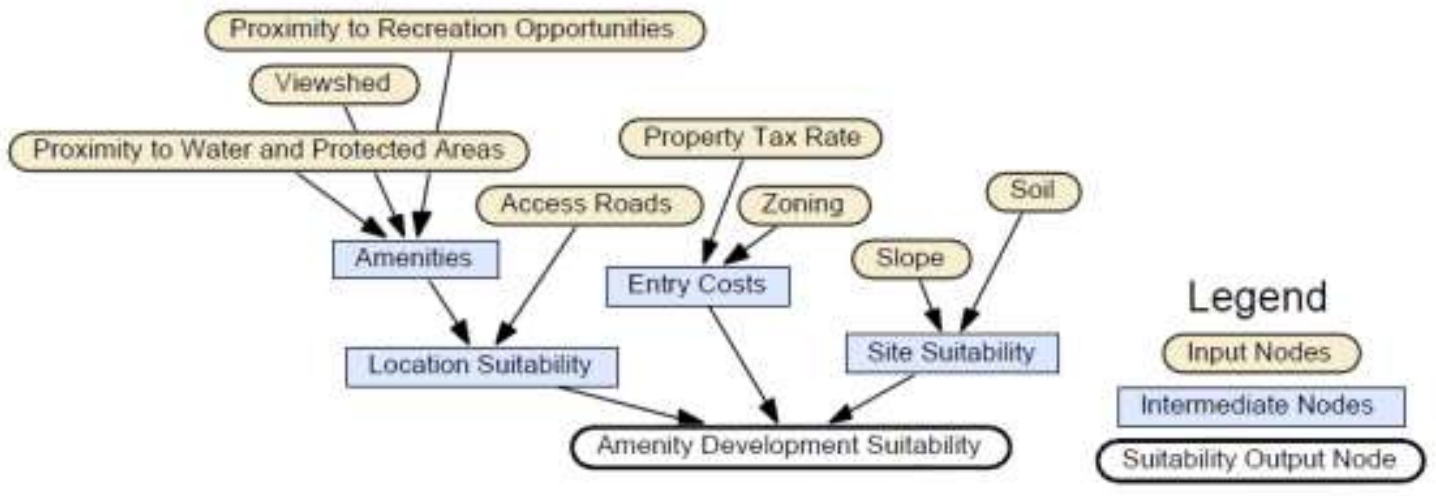


Figure 3 Bayesian network influence diagrams for development land uses in the Casco Bay and Lower Androscoggin Watershed (CBLA). Input nodes (yellow), intermediate nodes (blue) and the final outcome node (white) are shown for each of the $(A)$ residential development and (B) commercial development. (For interpretation of the referenced to color in this figure legend, the reader is referred to the final published version of this article.)

\section{CBLA}

\section{A. Residential Development}

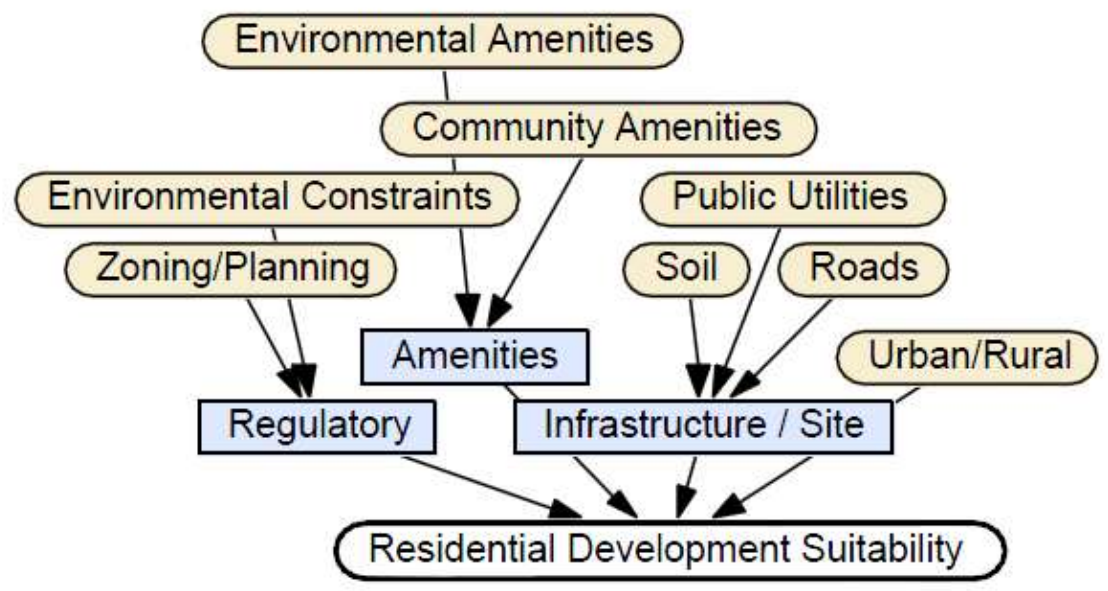

B. Commercial Development

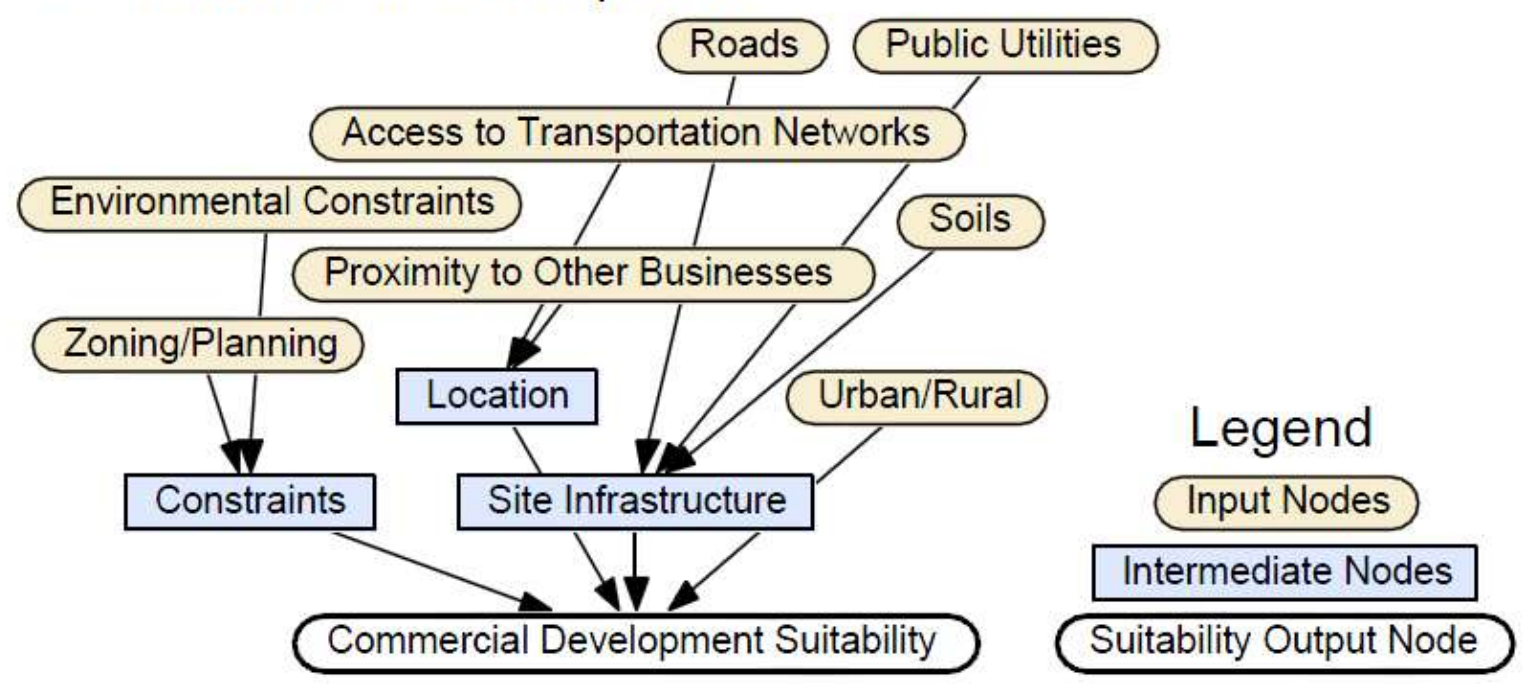


Figure 4 Bayesian network influence diagrams for forestry, agriculture and conservation land uses in the Lower Penobscot River Watershed (LPRW). Input nodes (yellow), intermediate nodes (blue), and the final outcome node (white) are shown for each of the (A) forestry, (B) agriculture, (C) conservation-local, and (D) conservation-landscape. (For interpretation of the references to color in this figure legend, the reader is referred to the final published version of this article.)

\section{A. Forest Management}

\section{LPRW}
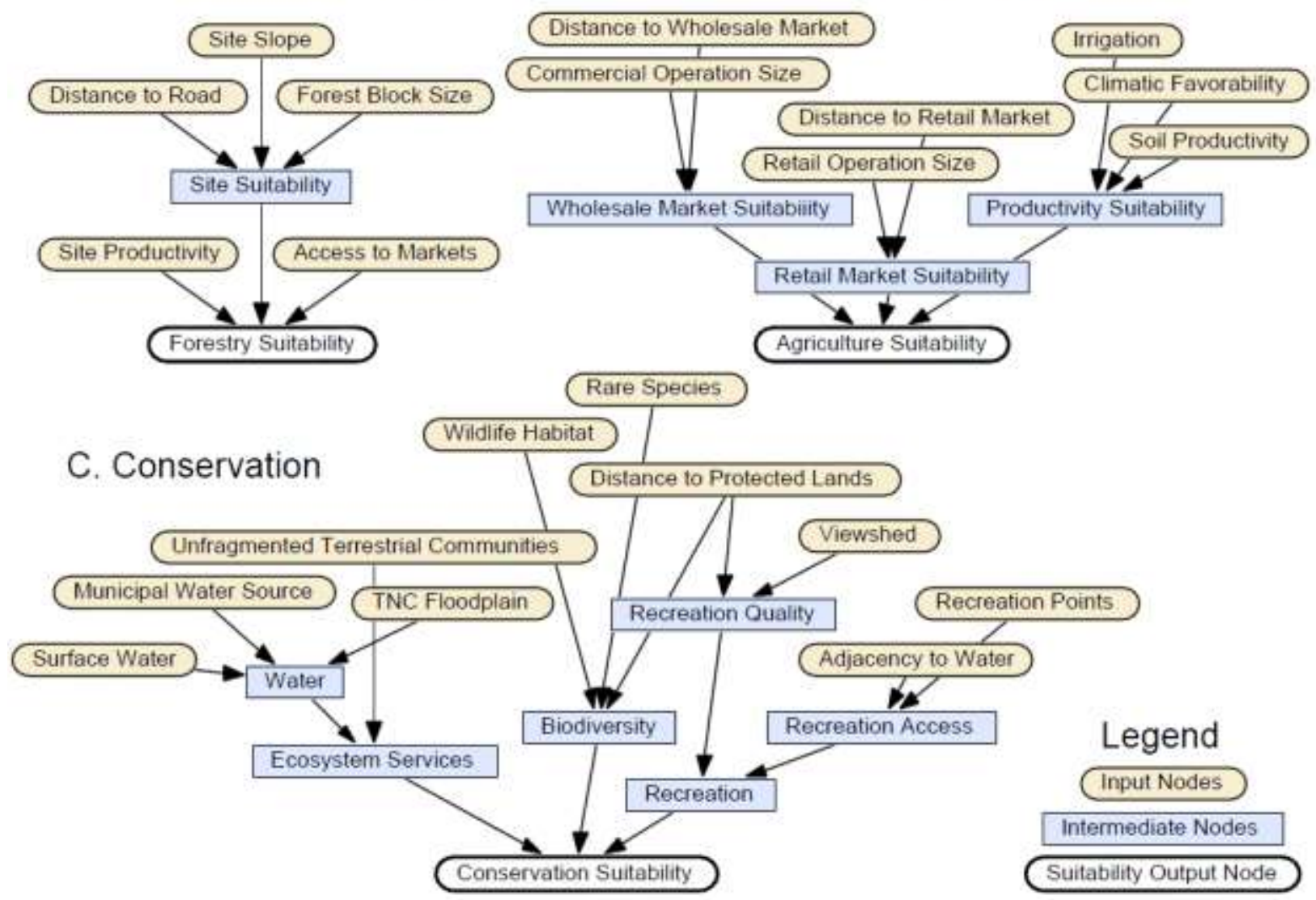
Figure 5 Bayesian network influence diagrams doe forestry, agriculture and conservation land uses in the Casco bay and Lower Androscoggin River Watershed (CBLA). Input nodes (yellow), intermediate nodes (blue), and the final outcome node (white) are shown for each of the (A) forestry, (B) agriculture, (C) conservation- local, and (D) conservation-landscape. (For interpretation of the references to color in this figure legend, the reader is referred to the final published version of this article.)

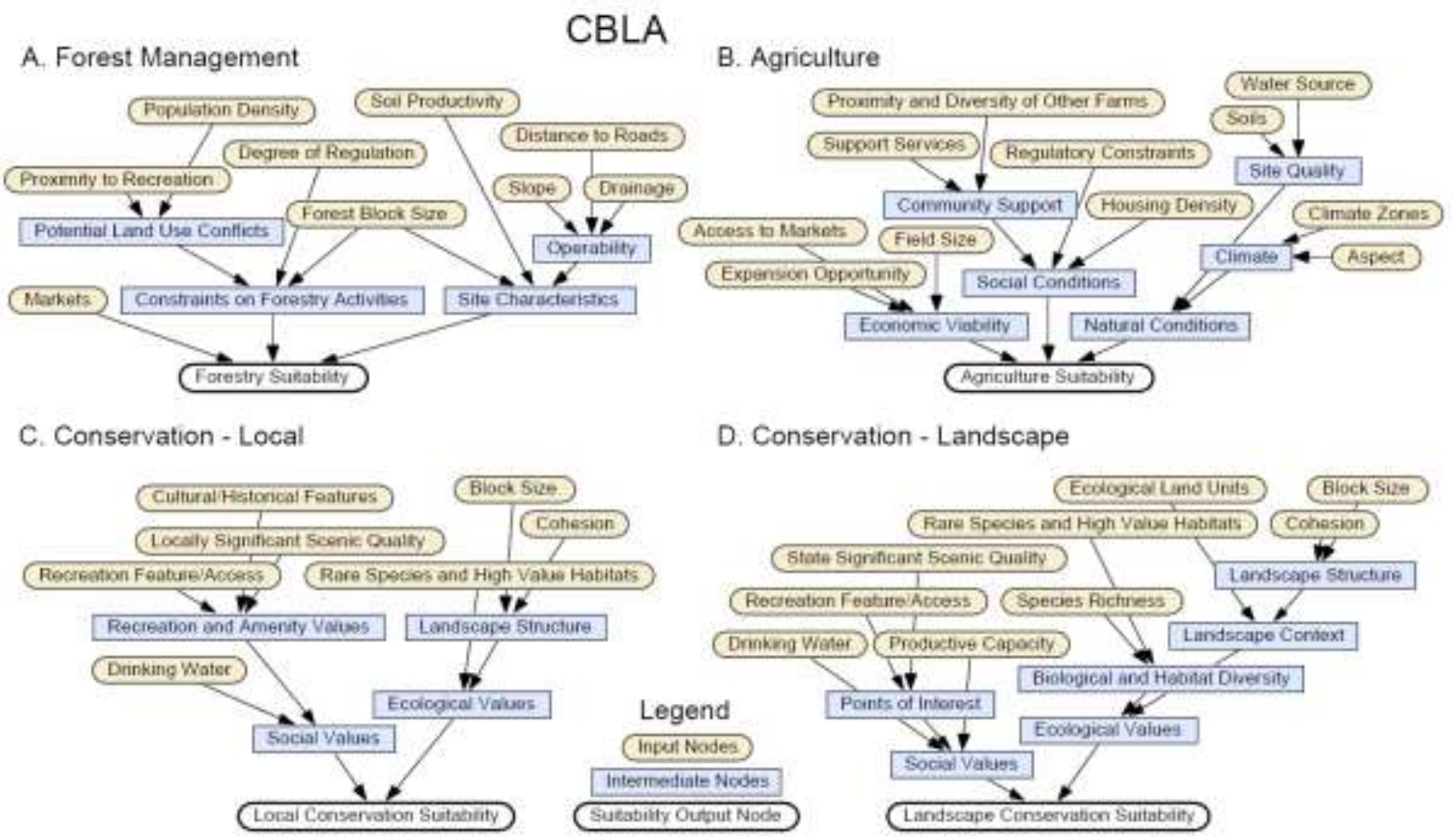


Table 2. Scale used to convert stakeholder-elicited, 5-point interval rankings to conditional probabilities in Bayesian networks (BN) for each land use. Some BN nodes have two states (e.g., near/far), while others use three (e.g., small/medium/large). Likert score bins have equal intervals, except for the three middle bins that were separated by the coefficient of variation $\left(C_{v}\right)$.

\begin{tabular}{|c|c|c|c|c|c|c|}
\hline & \multicolumn{3}{|c|}{$\begin{array}{c}\text { Interval Score } \\
\text { Ranges }\end{array}$} & \multicolumn{3}{|c|}{$\begin{array}{c}\text { Percent Probability } \\
\text { Distributions }\end{array}$} \\
\hline & Min. & Max. & $C_{v}$ & High & Medium & Low \\
\hline Two-State & 1 & 1.8 & & 100 & & 0 \\
\hline \multirow[t]{4}{*}{ Nodes } & 1.8 & 2.6 & & 75 & & 25 \\
\hline & 2.6 & 3.3 & & 50 & & 50 \\
\hline & 3.3 & 4.2 & & 25 & & 75 \\
\hline & 4.2 & 5 & & 0 & & 100 \\
\hline \multirow{11}{*}{$\begin{array}{l}\text { Three-State } \\
\text { Nodes }\end{array}$} & 1 & 1.1 & & 100 & 0 & 0 \\
\hline & 1.1 & 1.6 & & 75 & 25 & 0 \\
\hline & 1.6 & 2.2 & & 50 & 50 & 0 \\
\hline & 2.2 & 2.8 & & 25 & 75 & 0 \\
\hline & 2.8 & 3.2 & $<0.2$ & 0 & 100 & 0 \\
\hline & 2.8 & 3.2 & $0.2-0.5$ & 25 & 50 & 25 \\
\hline & 2.8 & 3.2 & $>0.5$ & 33 & 34 & 33 \\
\hline & 3.2 & 3.8 & & 0 & 75 & 25 \\
\hline & 3.8 & 4.4 & & 0 & 50 & 50 \\
\hline & 4.4 & 4.9 & & 0 & 25 & 75 \\
\hline & 4.9 & 5 & & 0 & 0 & 100 \\
\hline
\end{tabular}


Figure 6 Distribution of the land use suitability surface across each of the four land use categories in the Lower Penobscot River Watershed (LPRW). Darker colors indicate higher suitability based on Bayesian network models. Unavailable areas were excluded from the maps due to protection status (e.g., existing voluntary or regulatory-based protection) or open water. Note that some existing protected areas allow forestry and agriculture activities.

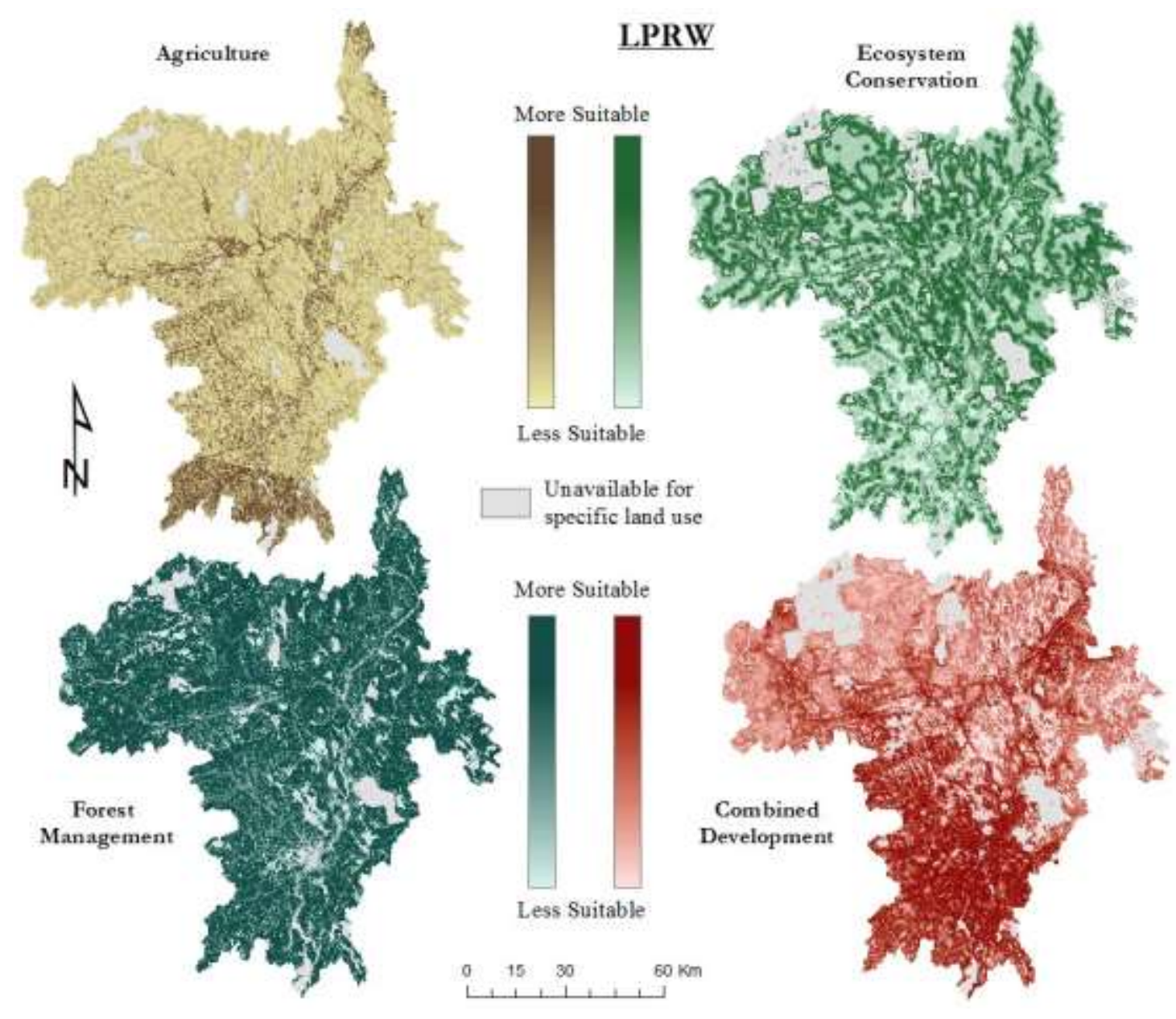


Figure 7 Distribution of the land use suitability surface across each of the four land use categories in the Casco Bay and Lower Androscoggin Watershed (CBLA). Darker colors indicate higher suitability based on Bayesian network models. Unavailable areas were excluded from the maps due to protection status (e.g., existing voluntary or regulatory-based protection) or open water. Note that some existing protected areas allow forestry and agriculture activities.

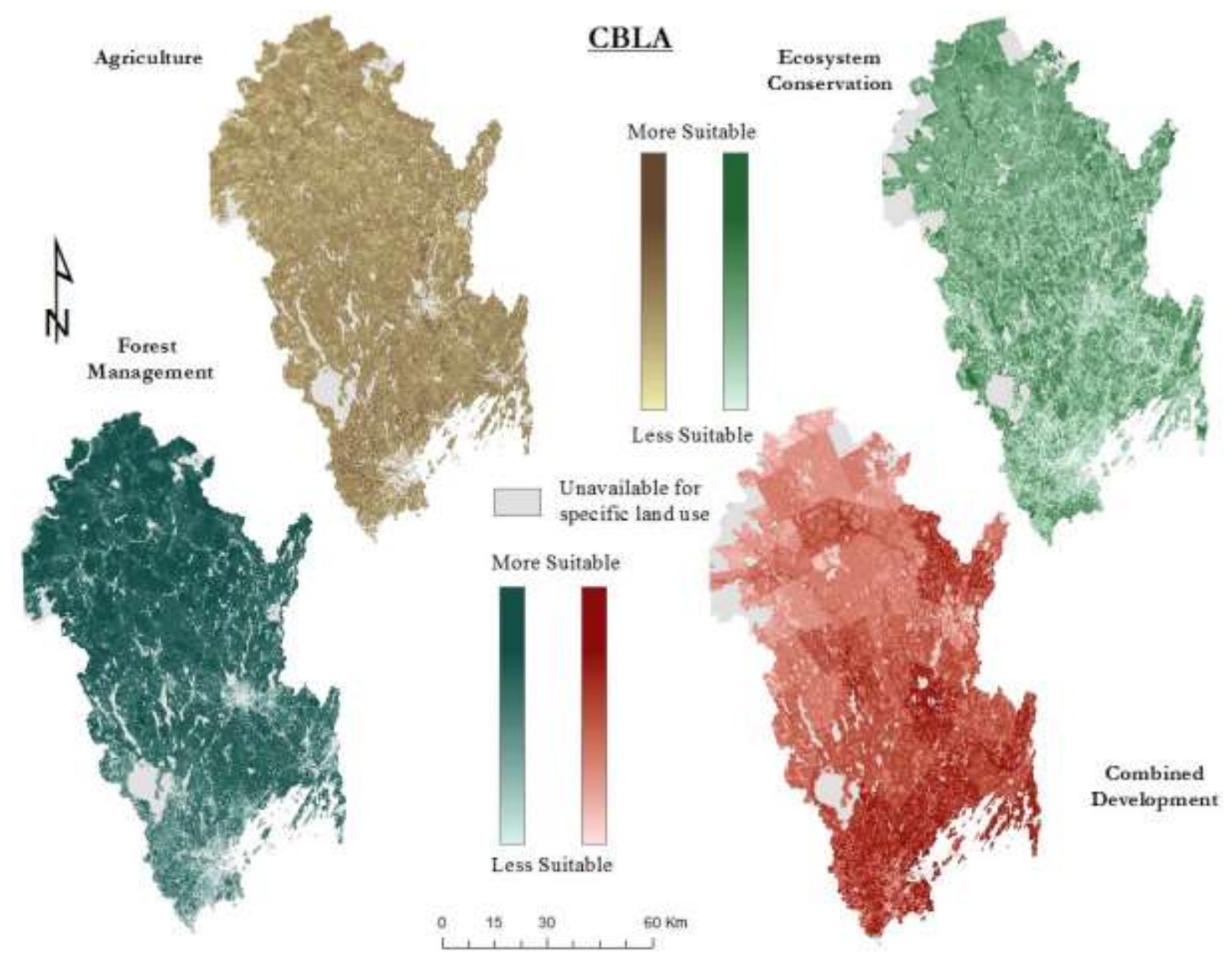


Table 3. Quantity of land that is: (1) available; and (2) highly suitable for each land use in the Lower Penobscot River Watershed (LPRW) and the Casco Bay and Lower Androscoggin Watershed (CBLA). See text for explanation of land considered unavailable for each land use.

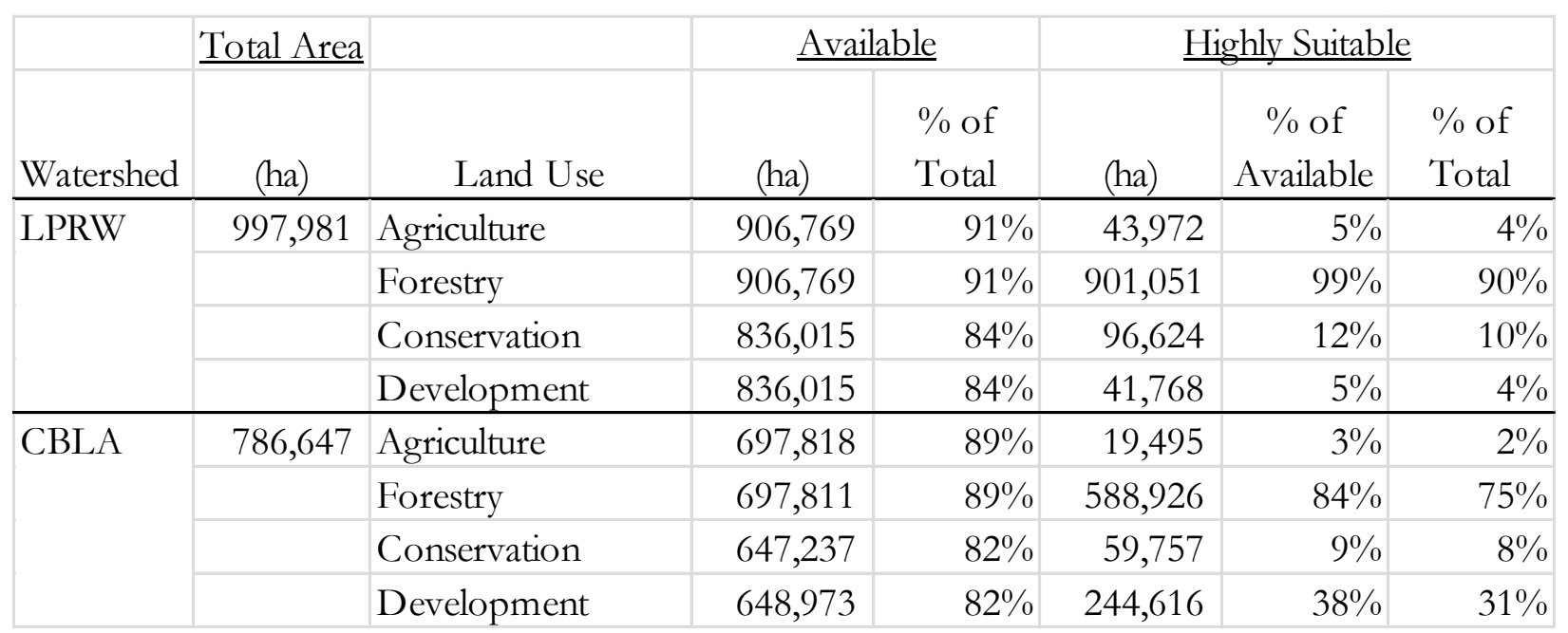


Table 4. Metrics of model complexity for each Bayesian network for both study areas: the Lower Penobscot River Watershed (LPRW) and the Casco Bay and Lower Androscoggin Watershed (CBLA). See Marcot (2012) for computation of the number of conditional probabilities.

\begin{tabular}{|c|c|c|c|c|c|}
\hline Watershed & \# of factors & \# of links & $\begin{array}{c}\text { Links:nodes } \\
\text { ratio } \\
\end{array}$ & $\begin{array}{c}\text { \# of } \\
\text { node states }\end{array}$ & $\begin{array}{c}\text { \# of conditional } \\
\text { probabilities }\end{array}$ \\
\hline \multicolumn{6}{|l|}{ LPRW } \\
\hline Residential Development & 10 & 15 & 1.50 & 40 & 159 \\
\hline Commercial Development & 7 & 9 & 1.29 & 26 & 162 \\
\hline Amenity Development & 8 & 12 & 1.50 & 32 & 150 \\
\hline Conservation & 10 & 17 & 1.70 & 39 & 162 \\
\hline Forestry & 5 & 6 & 1.20 & 18 & 90 \\
\hline Agriculture & 7 & 10 & 1.43 & 25 & 102 \\
\hline LPRW mean ( \pm s.e.) & $7.8( \pm 0.8)$ & $11.5( \pm 1.6)$ & $1.4( \pm 0.1)$ & $30( \pm 3.5)$ & $137.5( \pm 13.3)$ \\
\hline \multicolumn{6}{|l|}{$\overline{\text { CBLA }}$} \\
\hline Residential Development & 8 & 11 & 1.38 & 31 & 201 \\
\hline Commercial Development & 8 & 10 & 1.25 & 31 & 201 \\
\hline Local Conservation & 7 & 11 & 1.57 & 43 & 96 \\
\hline Landscape Conservation & 9 & 15 & 1.67 & 29 & 180 \\
\hline Forestry & 9 & 14 & 1.56 & 36 & 231 \\
\hline Agriculture & 11 & 17 & 1.55 & 47 & 246 \\
\hline CBLA mean ( \pm s.e. $)$ & $8.7( \pm 0.6)$ & $13( \pm 1.1)$ & $1.5( \pm 0.1)$ & $36.2( \pm 3)$ & $192.5( \pm 21.6)$ \\
\hline Total mean $( \pm$ s.e. $)$ & $8.3( \pm 0.5)$ & $12.3( \pm 1)$ & $1.5( \pm 0)$ & $33.1( \pm 2.4$ & $165( \pm 14.7)$ \\
\hline
\end{tabular}


Table 5. Sensitivity analysis based on entropy reduction reveals the relative order of importance of input nodes in each suitability model for Lower Penobscot River Watershed (LPRW) and Casco Bay and Lower Androscoggin Watershed (CBLA). A larger value implies that a given node exerts a stronger influence on the overall land use suitability of a specific pixel. Note that both the order of nodes and the magnitude of their importance varies considerably across land uses and watersheds.

\begin{tabular}{|c|c|c|c|c|}
\hline \multicolumn{2}{|r|}{ LPRW } & \multirow[b]{2}{*}{$\begin{array}{c}\text { Land Use } \\
\text { Model }\end{array}$} & \multicolumn{2}{|l|}{$\underline{\mathrm{CBLA}}$} \\
\hline $\begin{array}{c}\text { Entropy } \\
\text { Reduction }\end{array}$ & Nodes & & Nodes & $\begin{array}{c}\text { Entropy } \\
\text { Reduction }\end{array}$ \\
\hline 0.032 & Soils & \multirow{12}{*}{ Agriculture } & Climatic Favorability & 0.032 \\
\hline 0.024 & Distance to Retail Market & & Soils & 0.018 \\
\hline 0.016 & Distance to Wholesale Market & & Access to Markets & 0.013 \\
\hline 0.013 & Irrigation & & Aspect & 0.010 \\
\hline 0.013 & Climatic Favorability & & Water Source & 0.008 \\
\hline 0.006 & Retail Operation Size & & Expansion Opportunity & 0.004 \\
\hline \multirow[t]{6}{*}{0.004} & Commercial Operation Size & & Size of Fields & 0.003 \\
\hline & & & Regulatory Constraints & 0.002 \\
\hline & & & Climate Zones & 0.001 \\
\hline & & & Population Density & 0.001 \\
\hline & & & Support Services & 0.000 \\
\hline & & & Proximity/Diversity of Nearby Ag. & 0.000 \\
\hline 0.135 & Access to Markets & \multirow{9}{*}{$\begin{array}{c}\text { Forest } \\
\text { Management }\end{array}$} & Markets & 0.107 \\
\hline 0.074 & Site Productivity & & Soil Productivity & 0.016 \\
\hline 0.049 & Slope & & Forest Block Size & 0.009 \\
\hline 0.013 & Forest Block Size & & Slope & 0.006 \\
\hline \multirow[t]{5}{*}{0.012} & Distance to Roads & & Drainage & 0.002 \\
\hline & & & Distance to Roads & 0.002 \\
\hline & & & Population Density & 0.001 \\
\hline & & & Degree of Regulation & 0.000 \\
\hline & & & Proximity to Recreation & 0.000 \\
\hline 0.026 & Distance to Protected Lands & \multirow{9}{*}{$\begin{array}{l}\text { Conservation - } \\
\text { Landscape }\end{array}$} & Rare and Exemplary Habitats & 0.026 \\
\hline 0.021 & Unfrag. Terrestrial Communities & & Ecological Land Units & 0.013 \\
\hline 0.011 & Rare Species & & Drinking Water & 0.013 \\
\hline 0.005 & Adjacency to Water & & Block Size & 0.010 \\
\hline 0.004 & Wildlife Habitat & & Productive Capacity & 0.009 \\
\hline 0.001 & TNC Floodplain & & Species Richness & 0.008 \\
\hline 0.001 & Surface Water & & Recreation Access/Features & 0.003 \\
\hline 0.001 & Municipal Water Source & & Cohesion & 0.002 \\
\hline \multirow[t]{8}{*}{0.001} & Viewshed & & Scenic Quality & 0.002 \\
\hline & & \multirow{7}{*}{$\begin{array}{c}\text { Conservation - } \\
\text { Local }\end{array}$} & Rare Species \& High Value Hab. & 0.034 \\
\hline & & & Drinking Water & 0.020 \\
\hline & & & Block Size & 0.014 \\
\hline & & & Recreation Access/Features & 0.006 \\
\hline & & & Cohesion & 0.006 \\
\hline & & & Scenic Quality & 0.004 \\
\hline & & & Cultural/Historical Features & 0.003 \\
\hline 0.159 & Infrastructure & \multirow{8}{*}{$\begin{array}{l}\text { Commercial } \\
\text { Development }\end{array}$} & Access to Transportation & 0.013 \\
\hline 0.020 & Ability to Distribute & & Proximity to Other Businesses & 0.003 \\
\hline 0.014 & Slope & & Urban/Rural & 0.002 \\
\hline 0.011 & Population & & Public Utilities & 0.002 \\
\hline 0.010 & Soils & & Roads & 0.001 \\
\hline 0.005 & Floodplain & & Soils & 0.001 \\
\hline \multirow[t]{2}{*}{0.005} & Proximity to Other Businesses & & Zoning/Planning & 0.000 \\
\hline & & & Environmental Constraints & 0.000 \\
\hline 0.024 & Slope & \multirow{10}{*}{$\begin{array}{c}\text { Residential } \\
\text { Development }\end{array}$} & Zoning/Planning & 0.015 \\
\hline 0.024 & Floodplain & & Environmental Constraints & 0.005 \\
\hline 0.023 & Soils & & Community Amenities & 0.004 \\
\hline 0.010 & Zoning/Planning & & Roads & 0.004 \\
\hline 0.010 & Property Tax Rate & & Environmental Amenities & 0.004 \\
\hline 0.003 & Roads & & Public Utilities & 0.003 \\
\hline 0.003 & Utilities & & Soils & 0.001 \\
\hline 0.002 & Education & & Urban/Rural & 0.000 \\
\hline 0.001 & Proximity to Amenities & & & \\
\hline 0.001 & Proximity to Service Center & & & \\
\hline 0.044 & Proximity to Amenities & \multirow{9}{*}{$\begin{array}{c}\text { Amenity } \\
\text { Development }\end{array}$} & & \\
\hline 0.029 & Soils & & & \\
\hline 0.015 & Access Roads & & & \\
\hline 0.011 & Slope & & & \\
\hline 0.008 & Viewshed & & & \\
\hline 0.008 & Prox. to Water and Prot. Areas & & & \\
\hline 0.007 & Prox. to Recreation Opportun. & & & \\
\hline 0.004 & Zoning/Planning & & & \\
\hline 0.001 & Property Tax Rate & & & \\
\hline
\end{tabular}


Figure 8 Comparison of predicted land suitability for development, conservation, agriculture, and forestry in the Lower Penobscot River Watershed (LPRW) and the Casco Bay and Lower Androscoggin Watershed (CBLA). Suitability scores were classified into high, medium, and low to correspond to the highest, middle, and lowest third of the possible scores for each suitability distribution. For example, with most land uses, high suitability is any area with a suitability score greater than or equal to 0.667 probability of suitability. For land uses that are composites of sub-models (amenity, commercial, and residential development) the intervals are apportioned equally. Note: In the agriculture map for LPRW, the large area of medium suitability (yellow) in the southern portion of the watershed is due to a more favorable climatic zone.

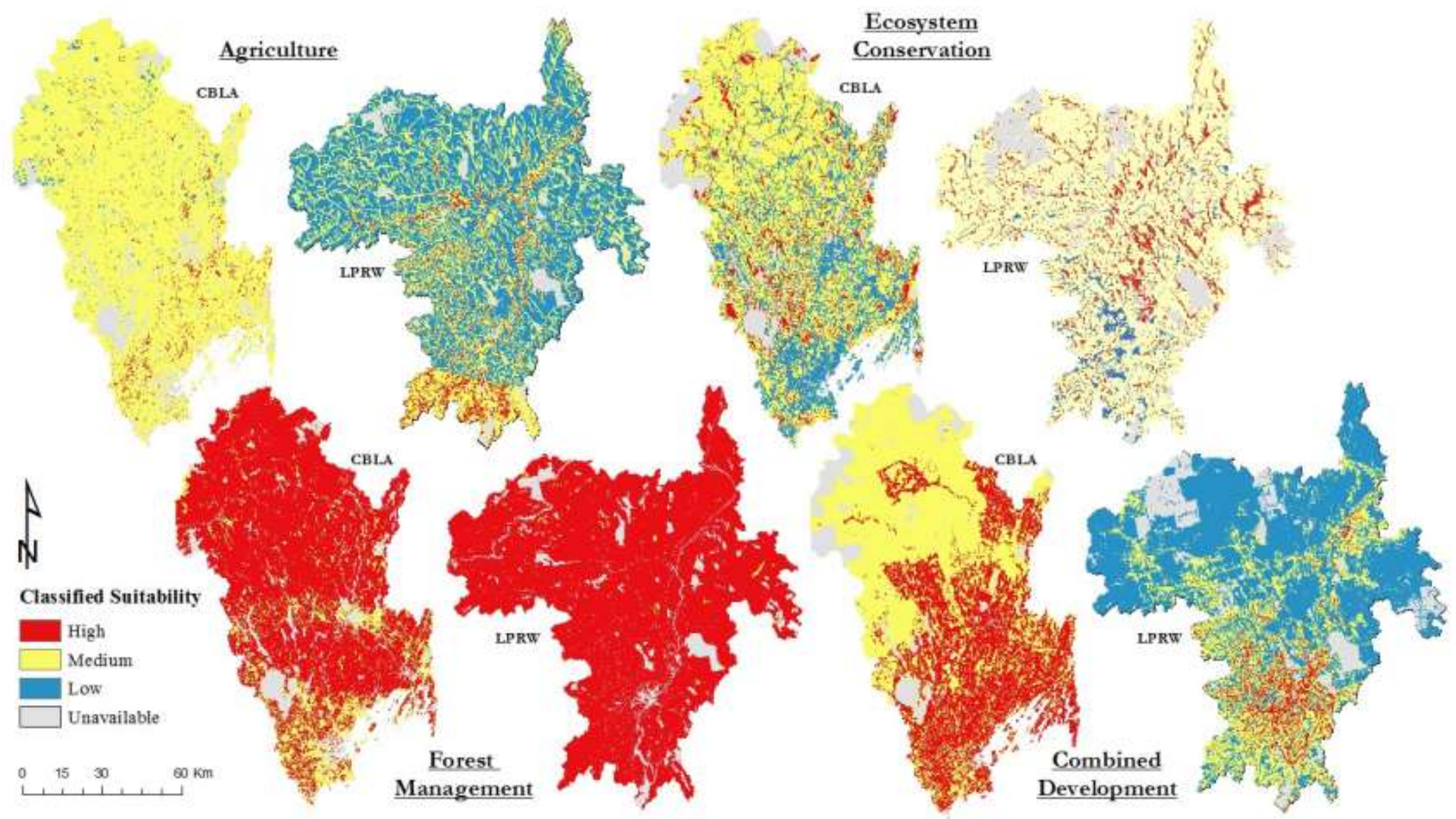

